\title{
Efficient water deluge nozzles arrangement on offshore installations for the suppression of pool fires
}

\author{
Dong Hun Lee ${ }^{\mathrm{a}}$, Jeom Kee Paik ${ }^{\mathrm{a}, \mathrm{b}, \mathrm{c}}$, Jung Kwan $\mathrm{Seo}^{\mathrm{b}^{*}}$ \\ ${ }^{a}$ Department of Naval Architecture and Ocean Engineering, Pusan National University, \\ Busan, Republic of Korea \\ ${ }^{\mathrm{b}}$ The Korea Ship and Offshore Research Institute, Pusan National University, Busan, \\ Republic of Korea \\ ${ }^{\mathrm{c}}$ Department of Mechanical Engineering, University College London, UK
}

${ }^{*}$ Corresponding author. Tel.: +82 51 510-2415. Email address: seojk@pusan.ac.kr (JK Seo).

\begin{abstract}
Offshore installations that handle hydrocarbons are in serious danger of fires and/or explosions. Pool fires are a significant risk related to major fire accidents, and active protection systems such as water deluge systems are used to reduce the consequences of high temperature and radiation resulting from pool fires. Thus, it is important to decide on the locations of water deluge nozzles for effective fire suppression, and the aim of this study is to introduce an efficient methodology for selecting the locations of water deluge nozzles. The locations of water deluge nozzles are selected using a proposed water deluge location index based on the characteristics of pool fires. The methodology is based on probabilistic approaches associated with credible scenarios representing possible events on offshore topside structures. This methodology, applied to examples, is used to determine the efficient arrangement of water deluge nozzles on a hypothetical FLNG topside structure. The effectiveness of the new methodology is verified through comparison with uniformly distributed nozzles using a computational fluid dynamics simulation.
\end{abstract}

Keywords: Offshore installations; pool fire; location of water deluge nozzles; water deluge location index.

\section{Introduction}

Onshore and offshore platforms have the potential for various hazardous risks. In particular, fires with high temperatures may result in catastrophic consequences such as significant human casualties, economic losses and serious environmental pollution. The fire risk assessment and 
management, which includes presented rules and recommended practices, have been identified for reducing the risk of fire accidents (Czujko and Paik, 2012a, 2012b; Spouge, 1999; NORSOK, 2010; ABS, 2014; LR, 2014). In addition, design guidelines have been established to detail the methods of fire risk assessment and management (Nolan, 1996; Walker et al., 2003; Vinnem, 2007; Paik and Czujko, 2009, 2010, 2011, 2012; Paik et al., 2011).

Risk control options are effective means of minimising the probability of an event and its associated risk (UKOOA/HSE, 2006). Generally, active protection devices such as gas detectors and water spray systems are used as preventive and/or mitigating safety systems against fire accidents. Most installations have a two-tier alert system for preventing spurious shutdowns and unnecessary alerts. System failures generally occur when a detector fails to detect the specified information such as flammable gas, flame, smoke, heat, toxic gas and oil mist, or when the alarm or signal transmission systems fail to alert operators or activate emergency mitigation systems (DeFriend et al., 2008).

Water deluge systems are designed to cool equipment and control the growth of a fire by providing a simultaneous application of water over the entire fire hazard (ISO, 1999). For the efficient application of such water deluge systems, the location of the water deluge nozzles is important for ensuring their performance. The locations of the water deluge nozzles are usually selected through engineering judgments based on the deterministic approach (Dembele et al., 2007). However, the conventional method has an element of uncertainty in light of human error and accidental fires. To reduce the risk of such uncertainty, a probabilistic approach, based on credible fire scenarios, becomes necessary to select the locations of water deluge nozzles.

Numerous studies of fire-fighting systems have been performed (Svensson, 2002; Himoto and Tanaka, 2012; Jee et al., 2013; Alarifi et al., 2014). McCaffrey (1984) investigated the effect of water deluge on jet fires, and Prasad et al. (1999) conducted an experimental test for the suppression of pool fires with water deluge systems. Gosse and Hankinson (2001) and Hankinson and Lowesmith (2004) carried out large-scale studies to investigate the mitigation effect of water deluge systems on jet and pool fires.

Regarding active protection systems, some research has contributed to the application of the probabilistic approach. Seo et al. (2013) introduced a method for determining efficient gas detector locations using a quantitative approach. Recently, Kim et al. (2016) stressed water deluge location in the control of jet fires, and successfully implemented the approximate optimisation method to calculate the efficient nozzle locations for offshore platforms. They 
suggested the use of a water deluge index, based on the characteristics of jet fires, to determine the efficient locations of water deluge nozzles. The present paper is a sequel to the previous paper (Kim et al., 2016). In contrast to the previous paper, which concerned jet fires, this paper focuses on pool fires. Pool fires have different characteristics than jet fires, and thus a proper method should be developed to reflect those characteristics. The aims of this study are to use the water deluge location index for pool fires (WLIP) to suggest an efficient method of arrangement based on a probabilistic approach, and to verify the effectiveness of the proposed methodology for the arrangement of water deluge nozzles. Finally, this study compares its results with current industrial practices.

\section{Methods for selecting water deluge nozzle location}

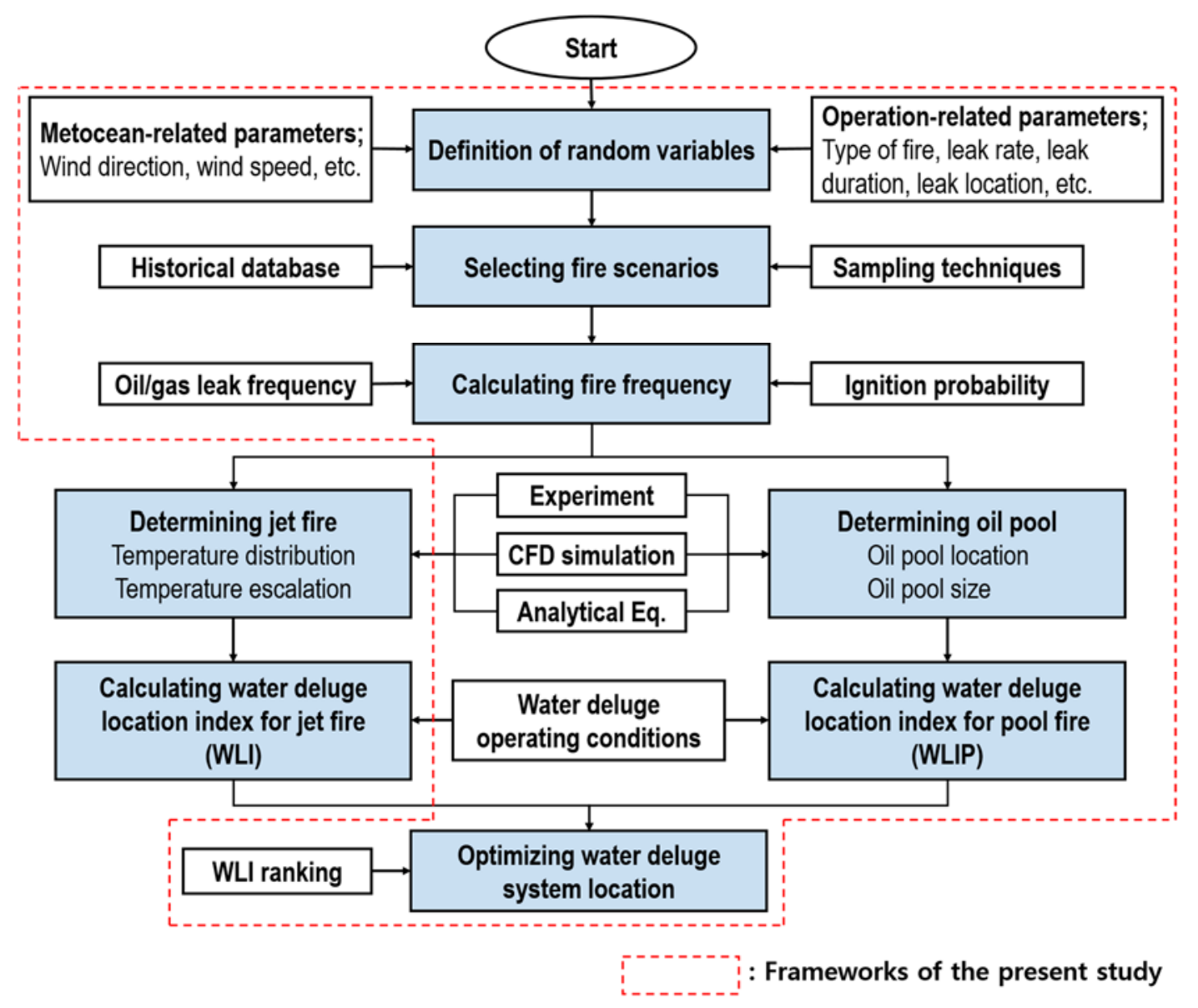

Fig. 1. Water deluge nozzle arrangement procedure for the control of jet (Kim et al. 2016) and pool fires

\subsection{Jet fires}

The location of water deluge nozzles has traditionally been determined based on engineering judgment and deterministic procedures. To reduce the risk of uncertainty in the conventional 
method, it is necessary to take a probabilistic approach based on engineering technology. Kim et al. (2016) successfully implemented a procedure for selecting efficient water deluge system locations to prevent, and reduce the consequences of, jet fire accidents on offshore installations. The WLI (water deluge index) is proposed to optimise water deluge nozzle locations.

The procedure is composed of six steps: 1) selecting credible fire scenarios; 2) simulating and/or experimentally testing fire CFD; 3 ) determining the consequences of fire loads (e.g., temperature-time history, temperature distribution and temperature escalation); 4) defining the operational temperatures for water deluge systems (e.g., reference temperatures); 5) calculating WLI; and 6) selecting optimised water deluge locations. However, WLI is calculated based on the variables that reflect the characteristics of the fire. Fig. 1 demonstrates the selection of a water deluge location for the control of jet/pool fires.

The major difference between jet fires and pool fires is the fire's momentum. Jet fires are pressurised releases of ignited hydrocarbons and have significant momentum. Pool fires with little or no initial momentum can be the result of ignition of vaporising hydrocarbon fuel. In the case of jet fires, fire direction (leak direction) and momentum are the major parameters that determine the spread of the fire. The authors' study is focused on jet fire accidents on offshore installations through the water deluge nozzle arrangement procedure (Fig. 1).

\subsection{Pool fires}

According to the application of optimization of nozzle against jet fires, the spread of pool fires, which have no or low momentum, is affected by the location and size of the oil pool and by the wind blowing effect. Thus, a proper method for the control of pool fires should be developed to reflect their characteristics. In the previous study, the WLI was calculated based on the results of the CFD jet fire simulation. In fact, without CFD simulation it becomes difficult to analyse the momentum of fires and the interaction between jet fires and their surrounding structures. In contrast, the interaction between pool fires and their surrounding structures can be ignored because pool fires have no momentum. Thus, CFD simulation is not needed for the calculation of WLI for pool fires.

The procedure of nozzle arrangement for pool fires is started from the random variables associated with fire events. An event which is characterised by random variables of influence may be formulated as a function of those random variables, as in Equation (1).

$$
\text { Event }=f\left(x_{1}, x_{2}, x_{3}, \cdots, x_{n}\right)
$$

Fire events may be characterised by metocean-related parameters (such as wind direction and 
wind speed) and operation-related parameters (such as leak rate and leak position), as shown in Fig. 1. In the next step, the scenarios for potential pool fires are selected using sampling techniques. To use a probabilistic sampling technique, the probability density functions of each random variable should be defined using relevant historical data. The fire frequencies of the selected scenarios are then calculated. The pool location and its size are estimated from each selected fire scenario using experiments, analytical equations or oil spill computational fluid dynamics (CFD) analysis.

Using the calculated fire frequencies, pool locations and pool sizes, the WLI of pool fires is calculated and ranked to select the final location of water deluge nozzles for the suppression of pool fires.

The selection of locations for water deluge nozzles is based on a ranking index known as the water deluge location index for pool fires (WLIP). This WLIP is calculated based on the variables that reflect the characteristics of pool fires. The location and size of an oil pool are prime variables that define the flame size and heat-affected area. The wind blowing effect is also a major variable related to flame size and the heat-affected area. However, the most effective location of water spray for suppressing pool fires is just above the oil pool. Thus, the WLIP for each candidate location is defined by Equation (2) and adopted to score each section.

$$
W L I P_{s}=\sum_{i=1}^{N}\left(A_{e f f i, i} \times F_{i}\right)
$$

where

$A_{\text {effi, }, \mathrm{i}}=$ efficiency value at each section

$\mathrm{s}=$ section number,

$\mathrm{i}=$ scenario number,

$\mathrm{N}=$ total number of scenarios and

$F_{i}=$ fire frequency of each pool fire scenario.

where

$$
A_{\text {eff }, i}=\frac{A_{\text {pool }, i}}{A_{\text {section }}}
$$

$\mathrm{A}_{\text {pool }, \mathrm{i}}=$ oil pool area in each section and

$\mathrm{A}_{\text {section }}=$ area of each section.

Fig. 2 illustrates the sections and the efficiency values at each section to calculate the WLIP. Each of the sections is a candidate location for the installation of water deluge nozzles. The 
sizes of each section should not exceed the capacity of the water spray (such as its radius). Based on these sizes, the Aeffi and WLIP are calculated and ranked to select the locations for the water deluge system. In addition, the pool sizes and shapes for each scenario should be estimated to calculate the Aeffi and WLIP. The pool's geometry can be estimated using an analytical equation or an oil spill CFD analysis.

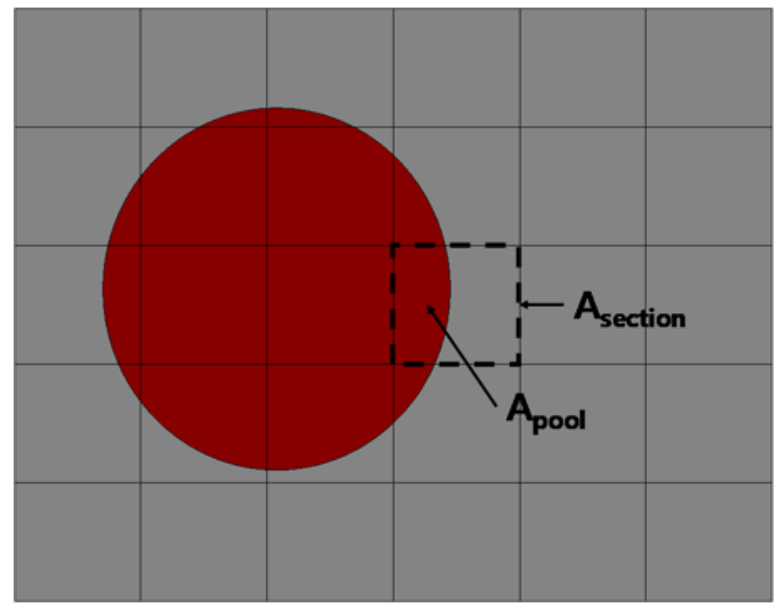

Fig. 2. Example of sections and calculation of efficiency values at each section to calculate the WLIP. (The circle represents an oil pool).

\section{Applied example for pool fire accident}

\subsection{Target Structure}

Part of a hypothetical FLNG topside structure, is used as the target structure in the applied example. It consists of one deck, called the process deck (Fig. 3).

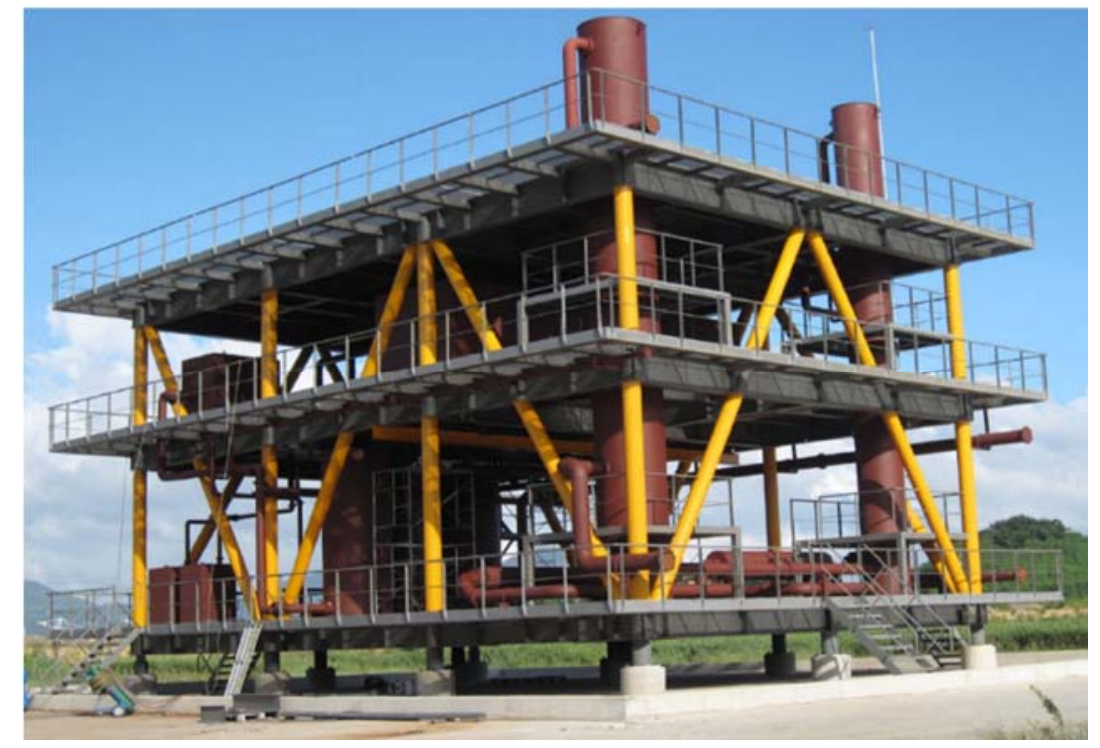

(a) Hypothetical FLNG topside structure at the KOSORI test site 


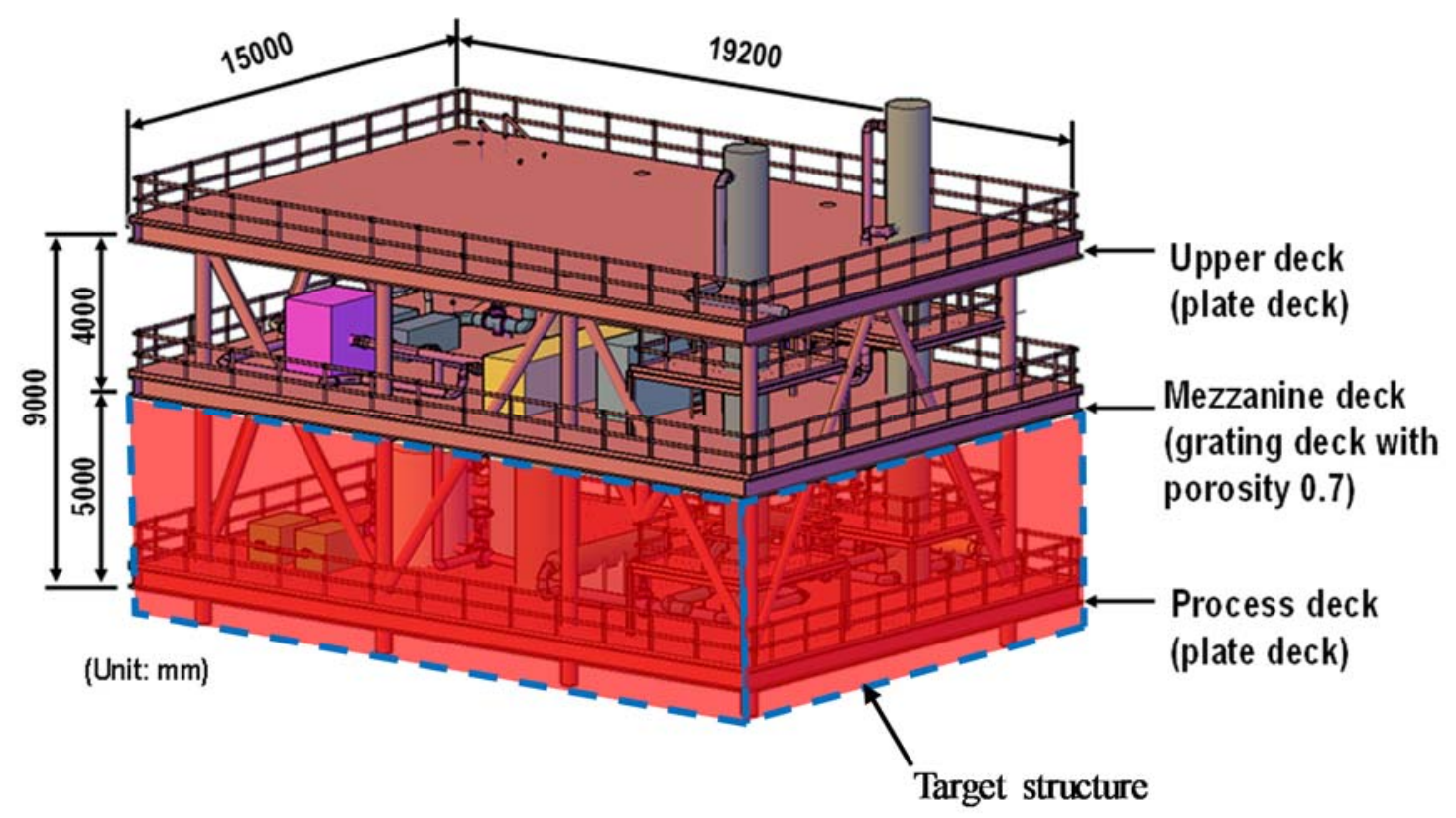

(b) Schematic of target structure

Fig. 3. Three-dimensional view of the FLNG topside separation module considered.

\subsection{Selection of fire scenarios}

The selection of a credible pool fire scenario is important for the determination of water spray positions. The Latin hypercube samplings (LHSs) technique (Ye, 1998) is used in this applied example for selecting the fire scenarios. The LHSs technique partitions each input distribution into $\mathrm{N}$ intervals of equal probability and selects one sample from each interval. In this study, the LHSs technique is selected because its sampling method is advantageous when the number of data is small.

Wind direction, wind speed, leak rate and leak position $(\mathrm{X}, \mathrm{Y})$ are considered as the random variables to select credible scenarios for the pool fires.

It is assumed that the structure is installed in the Hadong district of Korea. The metocean data of this district is used to determine the probability density functions of wind direction (clockwise from south) and wind speed.

The HSE (2000) and OGP (2010a) provide databases on the release frequencies for process deck equipment according to their type and size. Fig. 4 shows equipment on the process deck of the hypothetical FLNG topside structure, and Table 1 indicates the release frequencies for each type of equipment.

For convenience, it is assumed that the range of the leak positions in the $\mathrm{x}$ and $\mathrm{y}$ directions varies from 0 to 1 (Fig. 5 (d)). Five sectors with the same interval per sector are considered, in 
which the number of vessels and the amount of piping, along with their contribution to the probability density of the release, are evaluated. The release frequency of each sector is calculated by the sum of release frequencies of equipment located in each sector. If the $\mathrm{x}$ and $\mathrm{y}$ directions are not coincident with any equipment, the leak position is modified to a point on the nearest equipment to the selected leak position in terms of lineal distance.

The probability density of the leak rate is defined based on the historical database of HSE (2000).

Fig. 5 and Table 2 present the probability density functions (PDFs) of the selected five random variables for pool fire accidents. A goodness-of-fit (GOF) test by the Anderson-Darling (AD) method (Anderson and Darling, 1954) is applied to find the best distribution function enabling the fit of the overall database for each random variable.

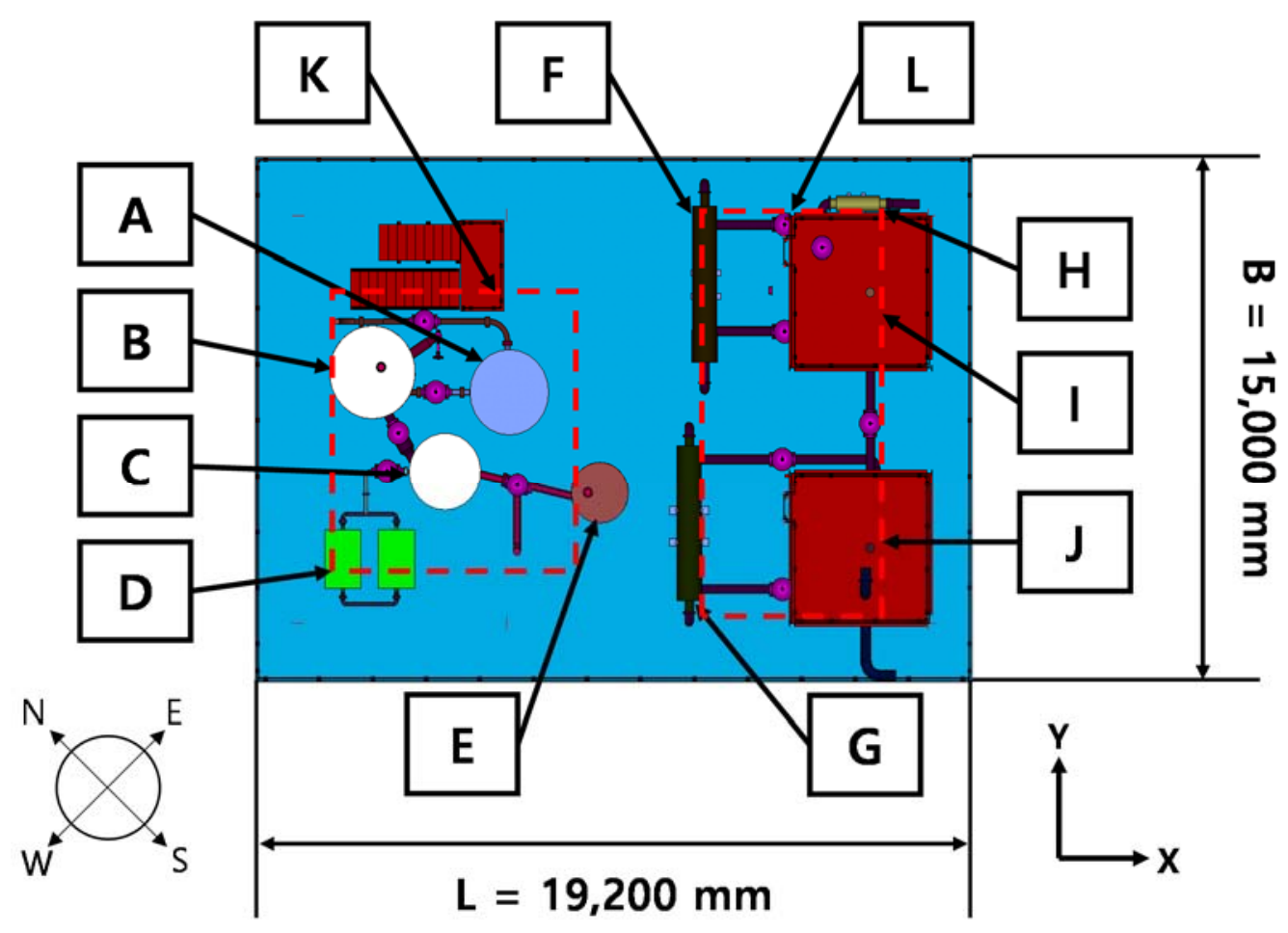

Fig. 4. Schematic of the process deck.

Table 1. Release frequencies of the equipment on the process deck.

\begin{tabular}{cccccc}
\hline \multirow{2}{*}{ Tag } & Description & \multicolumn{3}{c}{ Size $(\mathrm{m})$} & \multirow{2}{*}{$\begin{array}{c}\text { Release frequency } \\
\text { (/year) }\end{array}$} \\
\cline { 3 - 5 } & & W/Dia. & L/Dia. & H & $3.90 \mathrm{E}-03$ \\
\hline A & Surge drum & 2.2 & 2.2 & 5.8 & $3.90 \mathrm{E}-03$ \\
B & HP flash drum & 2.4 & 2.4 & 6.8 & $3.90 \mathrm{E}-03$ \\
C & LP flash drum & 2.0 & 2.0 & 5.9 &
\end{tabular}




\begin{tabular}{cccccc} 
D & Rundown pump A/B & 1.0 & 1.0 & 1.5 & $6.35 \mathrm{E}-03$ \\
E & Compressor suction drum & 1.6 & 1.6 & 6.8 & $1.30 \mathrm{E}-02$ \\
F & Stabilizer reboiler & 0.7 & 4.0 & 0.7 & $1.43 \mathrm{E}-02$ \\
G & Demethanizer reboiler & 0.5 & 4.0 & 0.5 & $1.43 \mathrm{E}-02$ \\
H & Condensate cooler & 0.4 & 1.2 & 0.4 & $5.06 \mathrm{E}-03$ \\
I & Stabilizer & 1.4 & 1.4 & 12.5 & $1.03 \mathrm{E}-03$ \\
J & Demethanizer & 1.1 & 1.1 & 12.5 & $1.03 \mathrm{E}-03$ \\
K & Pipe (50 mm Dia) & - & - & - & $1.50 \mathrm{E}-04$ \\
L & Pipe (150 mm Dia) & - & - & - & $7.40 \mathrm{E}-04$ \\
\hline
\end{tabular}

Table 2. Probability density function of each random variable.

\begin{tabular}{cccc}
\hline Random variables & Distribution function & Parameters & AD value \\
\hline Wind direction & Normal & $\mu=180.9, \sigma=50.57$ & 1.327 \\
Wind speed & Weibull & $\alpha=4.840, \beta=2.563$ & 1.442 \\
Leak rate & 3-parameter weibull & $\alpha=29.390, \beta=1.454, \lambda=1.000$ & 2.939 \\
Leak position X & Weibull & $\alpha=0.5354, \beta=2.252$ & 1.503 \\
Leak position Y & Weibull & $\alpha=0.5120, \beta=1.687$ & 2.291 \\
\hline
\end{tabular}

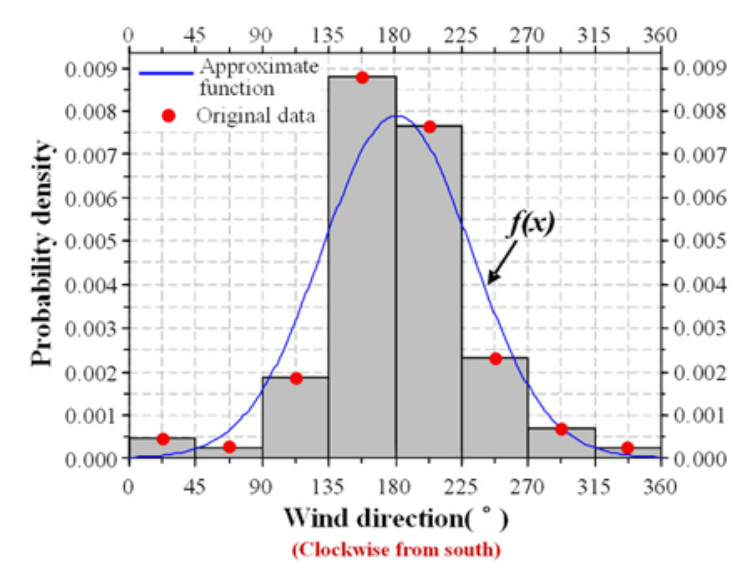

(a) Wind direction

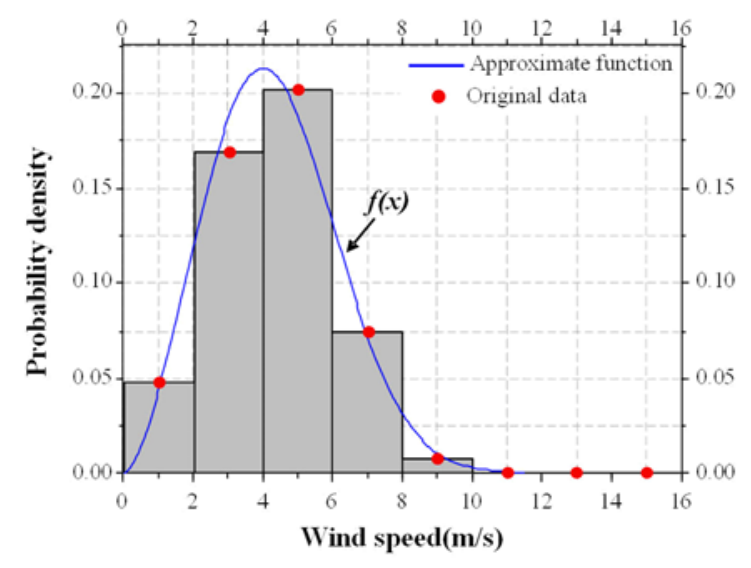

(b) Wind speed 


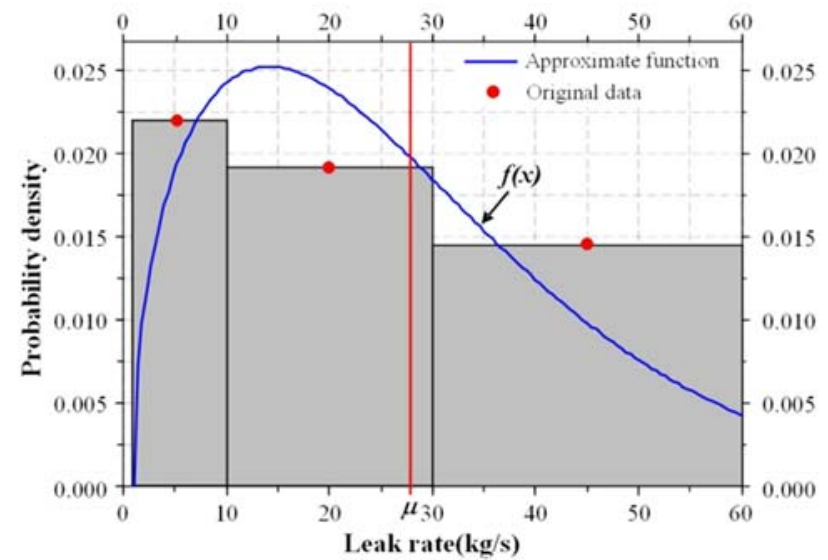

(c) Leak rate

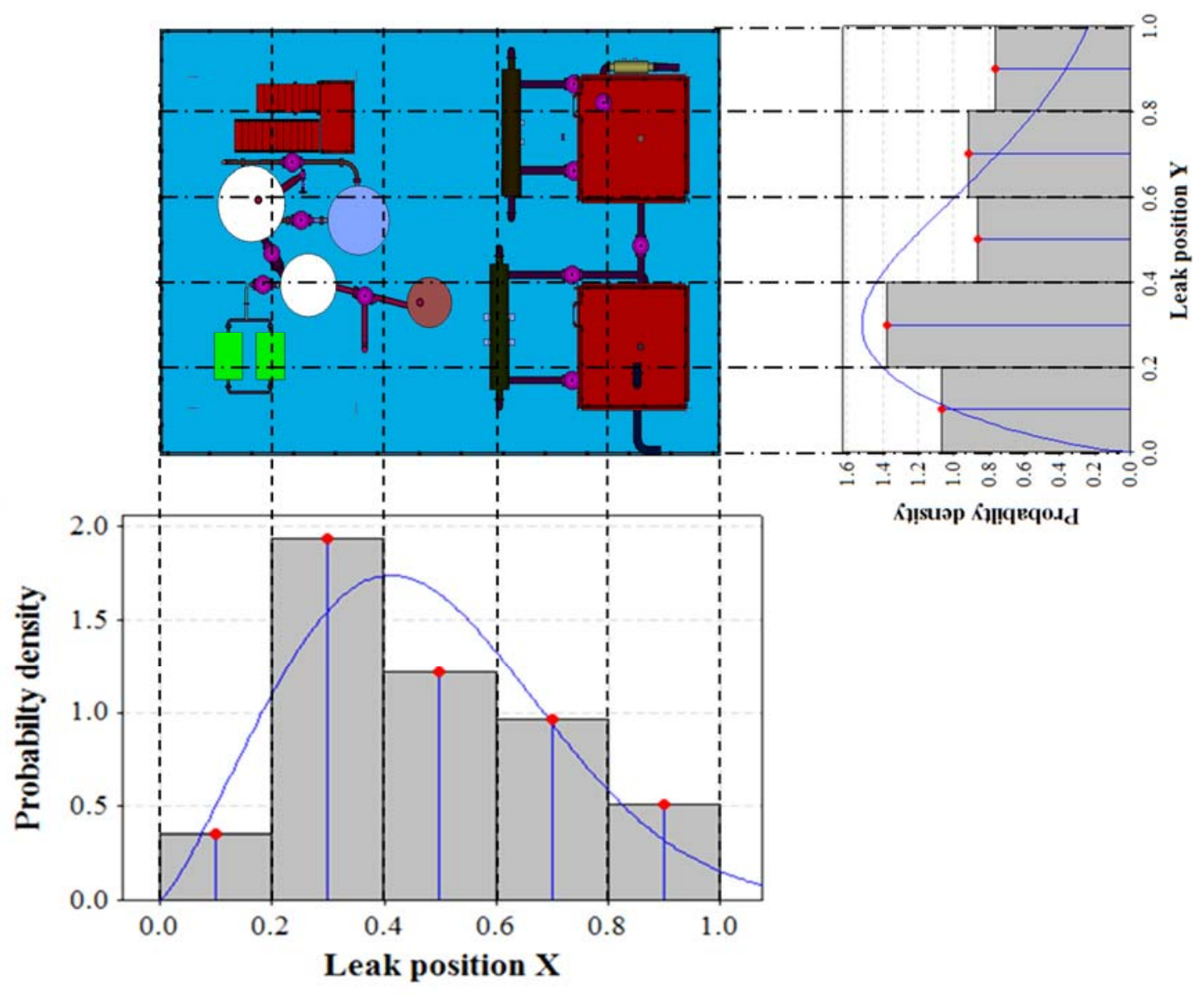

(d) Leak position X (X/L) and leak position $\mathrm{Y}(\mathrm{Y} / \mathrm{B})$

Fig. 5. Probability density function of each random variable.

Table 3 shows the 20 fire scenarios selected using the sampling technique with random variables. The fire frequencies can be calculated by Equation (4).

$$
\text { Fire frequency }=\text { Leak freqeuncy } \times \text { Ignition probability }
$$

The leak frequency is calculated by Equation (5). The probabilities of the random variables are 
independent of one another.

where

$$
\text { Leak freqeuncy }=F_{\text {release }} \times P_{w d} \times P_{w s} \times P_{\text {rate }}
$$

$F_{\text {release }}=$ release frequency of each piece of equipment,

$\mathrm{P}_{\mathrm{wd}}=$ probability of specific wind direction,

$\mathrm{P}_{\mathrm{ws}}=$ probability of specific wind speed and

$P_{\text {rate }}=$ probability of specific leak rate.

Table 3. Scenarios used.

\begin{tabular}{cccccccc}
\hline $\begin{array}{c}\text { No. of } \\
\text { sce. }\end{array}$ & $\begin{array}{c}\text { Wind } \\
\text { direction } \\
\left({ }^{\circ}\right)\end{array}$ & $\begin{array}{c}\text { Wind } \\
\text { speed } \\
(\mathrm{m} / \mathrm{s})\end{array}$ & $\begin{array}{c}\text { Leak } \\
\text { position } \\
\mathrm{X}(\mathrm{m})\end{array}$ & $\begin{array}{c}\text { Leak } \\
\text { position } \\
\mathrm{Y}(\mathrm{m})\end{array}$ & $\begin{array}{c}\text { Leak } \\
\text { rate } \\
(\mathrm{kg} / \mathrm{s})\end{array}$ & $\begin{array}{c}\text { Pool } \\
\text { diameter } \\
(\mathrm{m})\end{array}$ & $\begin{array}{c}\text { Fire } \\
\text { frequency } \\
(/ \mathrm{yr})\end{array}$ \\
\hline 1 & 38.39 & 4.36 & 14.38 & 9.08 & 0.91 & 5.01 & $1.1355 \mathrm{E}-07$ \\
2 & 258.68 & 3.25 & 14.66 & 6.31 & 0.26 & 2.68 & $1.0445 \mathrm{E}-07$ \\
3 & 83.04 & 2.53 & 16.58 & 7.58 & 4.03 & 10.55 & $1.2581 \mathrm{E}-05$ \\
4 & 203.69 & 4.18 & 4.45 & 3.48 & 0.22 & 2.46 & $1.0329 \mathrm{E}-07$ \\
5 & 70.46 & 1.30 & 3.43 & 11.51 & 0.23 & 2.52 & $5.8563 \mathrm{E}-06$ \\
6 & 229.12 & 3.11 & 8.78 & 5.05 & 0.01 & 0.53 & $8.4060 \mathrm{E}-08$ \\
7 & 104.65 & 4.55 & 5.14 & 4.11 & 12.00 & 18.20 & $9.7245 \mathrm{E}-05$ \\
8 & 195.67 & 5.94 & 6.91 & 7.90 & 3.04 & 9.16 & $1.0989 \mathrm{E}-05$ \\
9 & 248.14 & 4.01 & 7.40 & 7.60 & 0.73 & 4.49 & $1.1189 \mathrm{E}-05$ \\
10 & 148.60 & 2.68 & 7.26 & 6.26 & 0.57 & 3.97 & $6.2215 \mathrm{E}-06$ \\
11 & 123.38 & 5.25 & 2.55 & 7.60 & 0.08 & 1.49 & $9.6561 \mathrm{E}-08$ \\
12 & 132.07 & 3.55 & 14.10 & 6.52 & 1.13 & 5.59 & $1.0186 \mathrm{E}-06$ \\
13 & 15.08 & 3.85 & 15.52 & 3.41 & 6.43 & 13.32 & $9.5408 \mathrm{E}-06$ \\
14 & 283.26 & 0.58 & 12.12 & 9.03 & 5.38 & 12.19 & $8.5429 \mathrm{E}-06$ \\
15 & 187.79 & 2.82 & 11.86 & 4.83 & 0.15 & 2.04 & $1.0047 \mathrm{E}-05$ \\
16 & 140.45 & 2.23 & 3.14 & 4.11 & 0.74 & 4.52 & $8.6305 \mathrm{E}-06$ \\
17 & 238.34 & 4.99 & 14.10 & 4.52 & 1.79 & 7.03 & $2.3570 \mathrm{E}-05$ \\
19 & 220.33 & 1.02 & 15.86 & 10.39 & 4.65 & 11.33 & $7.6554 \mathrm{E}-05$ \\
& 156.57 & 2.07 & 15.86 & 10.38 & 0.69 & 4.36 & $1.1535 \mathrm{E}-05$ \\
& 317.09 & 1.72 & 15.51 & 12.13 & 3.26 & 9.49 & $1.3796 \mathrm{E}-05$ \\
\hline
\end{tabular}


The PDF for leak rate is defined based on the historical database (HSE, 2000). The existing topside structures are generally over $30 \times 30 \mathrm{~m}$ in size. However, the target structure of this study is only 19.2 x $15 \mathrm{~m}$ in size. The equipment volumes are also relatively smaller than real equipment on topside structures. Thus, the mean value of the leak rate, $29.39 \mathrm{~kg} / \mathrm{s}$, is excessive in terms of the size of the target structure. As such, the leak rates of selected scenarios are scaled down at the same rate, so that the largest oil pool of selected scenarios does not exceed the length and breadth of the target structure. Although this is not the standard procedure, it is performed for reasonable validation of the developed method.

The release frequency of equipment, which is located at the selected leak position X, Y of each scenario, is used to calculate fire frequency. The probability of ignition is defined based on the 'offshore process liquid model' suggested by OGP (2010b). This model is the simplified lookup correlation of the 'UKOOA ignition model' (UKOOA, 2006). Also, this model can be applied to the release of flammable liquids that do not have any significant flash fraction $(10 \%$ or less) within offshore process modules. Fig. 6 presents the ignition probability adopted in this study.

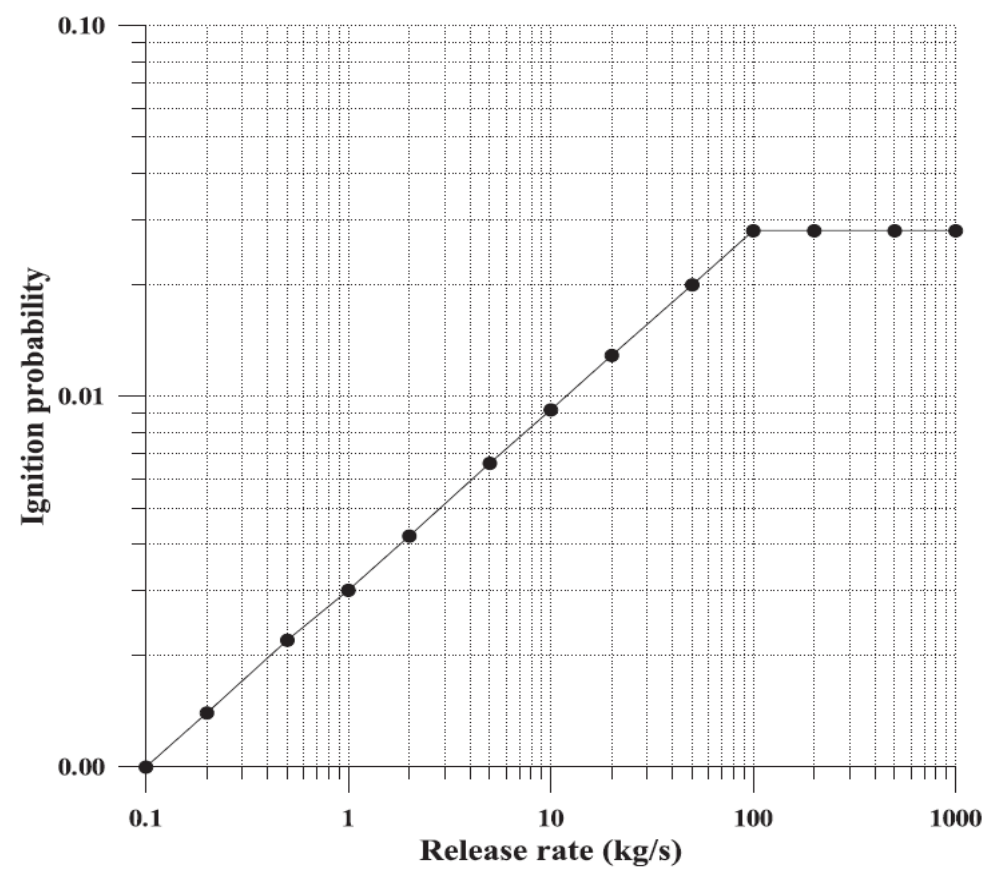

Fig. 6. Ignition probability (OGP, 2010).

\subsection{Definitions of oil pool location and size}

The pool locations and sizes for each scenario in Table 1 are defined based on the following assumptions: 
- Contained liquid is diesel (density $\left.=830 \mathrm{~kg} / \mathrm{m}^{3}\right)$.

- Oil pool depth is $2.5 \mathrm{~mm}$.

- The operating radius of water deluge is $3.5 \mathrm{~m}$.

- The safety device (ESD) activation time is 45 seconds (min. requirement in API, 2017).

The angle range of the common open-type deluge nozzle is $60 \sim 150^{\circ}$. Also, deluge nozzles are generally installed at a height of $2.5 \sim 3.5 \mathrm{~m}$ above the deck floor. In this study, it is assumed that the angle range of the water deluge nozzle is $60^{\circ}$ and that the water deluge nozzles are installed at a height of $3 \mathrm{~m}$. The sizes of the candidate sections for water nozzle installation are determined according to the operating radius of the water deluge, allowing the various operating radiuses to be applied to the developed methodology.

In this applied example, an analytical equation is used to estimate oil pool sizes. Based on the leak rate of each fire scenario, pool size was calculated using Equation (6), with liquid density, oil pool depth and a leak duration of 45 seconds.

Typically, the shape of a pool fire is presumed to be cylindrical (Cook et al., 1990; Mudan and Croce, 1995), based on the shape of an oil pool. This shape can be idealised as circular. The radius of oil pool $(\mathrm{r})$ is given by

$$
r(t)=\sqrt{\frac{M_{p o o l}(t)}{\pi \cdot h(t) \cdot \rho}}
$$

where

$$
\begin{aligned}
& \mathrm{t}=\text { time }(\mathrm{s}) \\
& \mathrm{M}_{\text {pool }}=\text { mass of the pool }(\mathrm{kg}), \\
& \pi=\text { circular constant, } \\
& \mathrm{h}=\text { uniform thickness of the pool }(\mathrm{m}) \text { and } \\
& \rho=\text { liquid density }\left(\mathrm{kg} / \mathrm{m}^{3}\right) .
\end{aligned}
$$

Fig. 7 shows the calculated oil pool locations and sizes for each scenario. Oil spill CFD analysis can be used to estimate the pool location and size and may yield more accurate results. 

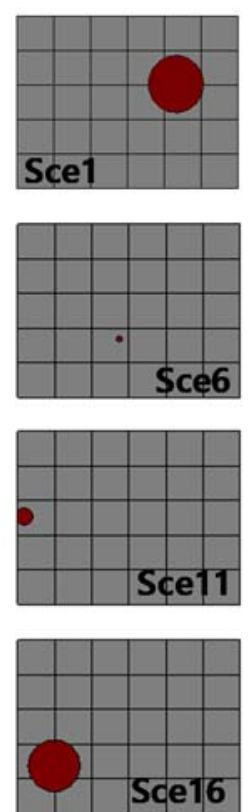
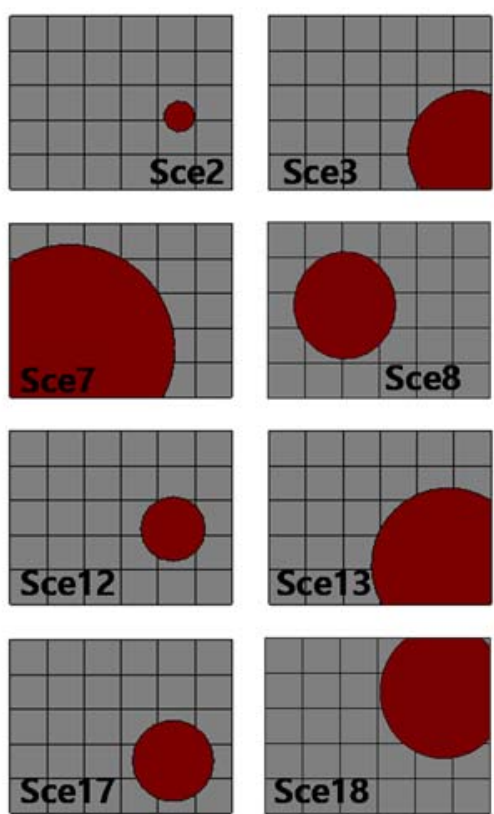
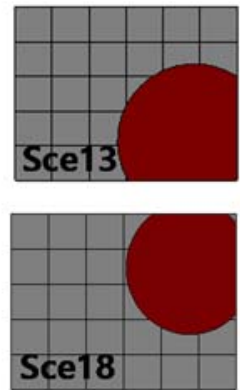
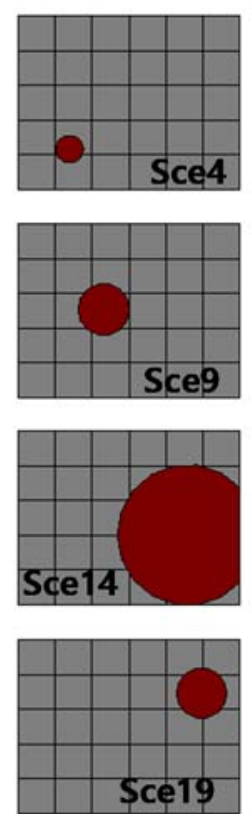
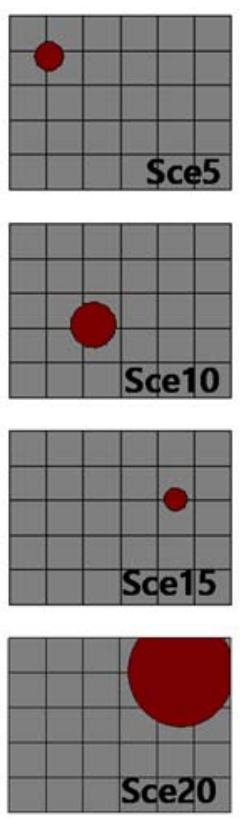

Fig. 7. Oil pool locations and sizes for each scenario.

\subsection{Selection of water deluge system locations}

\subsubsection{WLIP}

In this step, the WLIP is calculated to select the position of the water deluge nozzles. To calculate the WLIP, the space on offshore installations should be divided into proper sizes. Then, each divided space (section) becomes a candidate position for water deluge nozzles.

In this study, it is assumed that the operating radius of a water nozzle is $3.5 \mathrm{~m}$. This radius should cover each of the section areas. Based on the capacity of a water nozzle, the space is divided to define the sections as shown in Fig. 8.

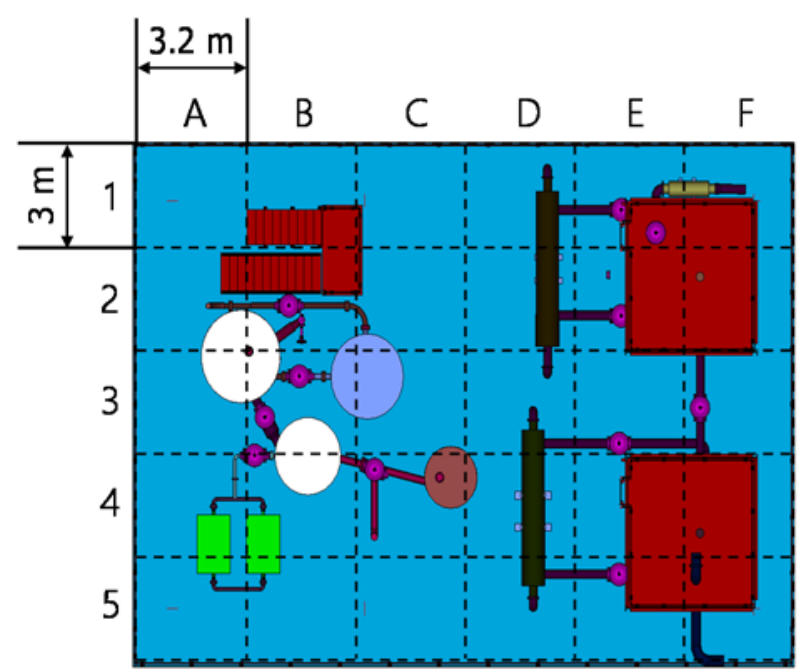

Fig. 8. Divided areas for WLIP calculation. 
The WLIP is defined as the product of the $A_{\text {effi }}$ of each section (in Fig. 9) and the fire frequency of each fire scenario (in Table 2) using Equation (1). Fig. 10 and Table 4 indicate the calculation results of Aeffi and WLIP at each section. Section E5 is in $3^{\text {rd }}$ place in the sum of Aeffi, however, section E5 is in $24^{\text {th }}$ place in the WLIP rank because the fire frequencies of the scenarios which have an effect on section E5 are relatively small. This means that the locations with a low probability of having pool fires may be excluded from selection by the WLIP.

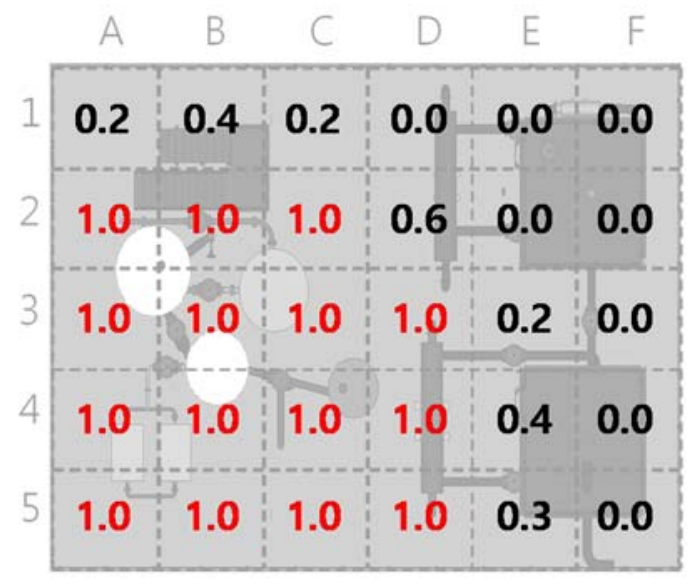

(a) Scenario 7

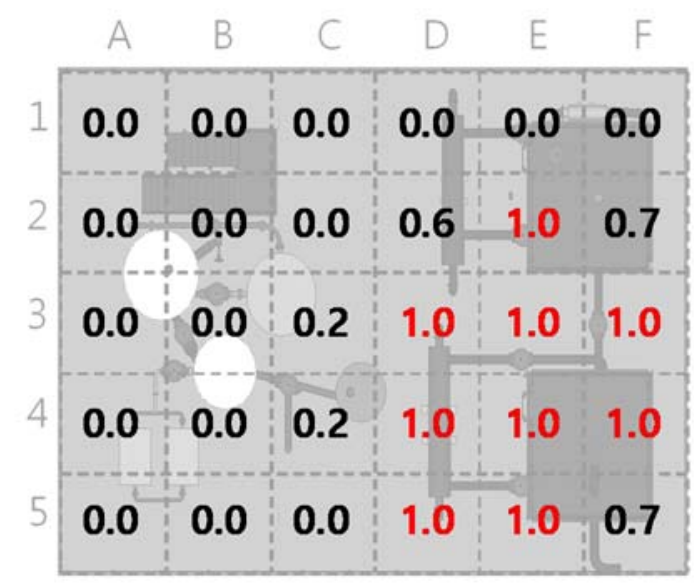

(b) Scenario 14

Fig. 9. The Aeffi of each section in scenarios 7 and 14.

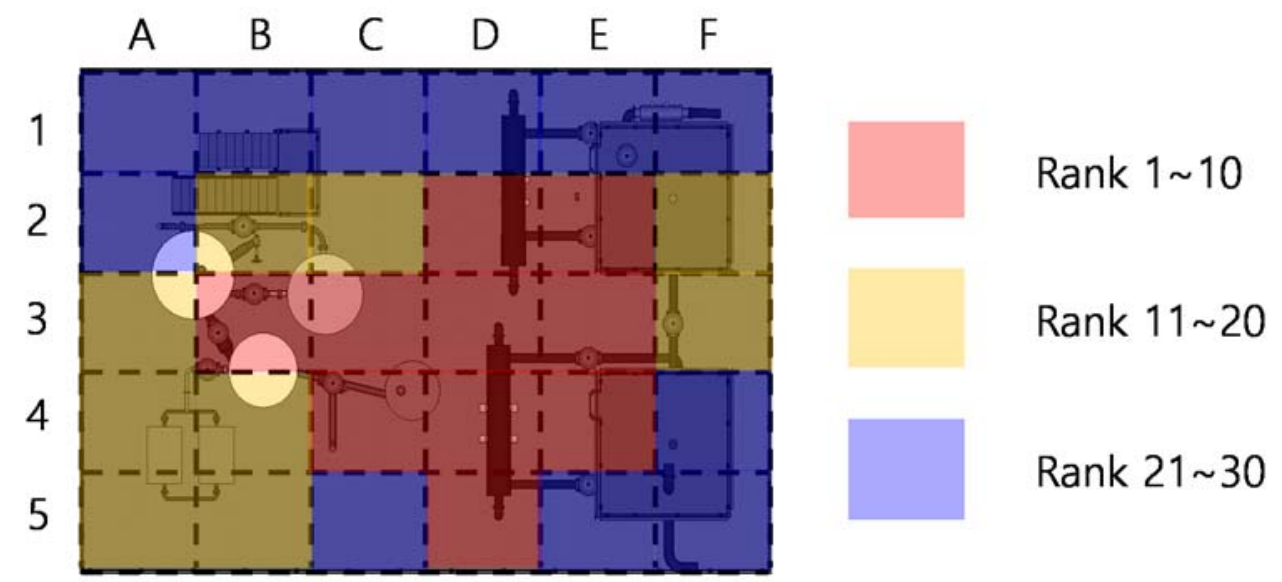

Fig. 10. WLIP rank of each candidate location. (This figure is available in colour on-line.)

Table 4. Calculation result of Aeffi and WLIP at each section.

\begin{tabular}{ccccc|ccccc}
\hline Section & $\begin{array}{c}\text { Sum } \\
\text { of } A_{\text {effi }}\end{array}$ & $\begin{array}{c}\mathrm{A}_{\text {effi }} \\
\text { rank }\end{array}$ & $\begin{array}{c}\text { WLIP } \\
\left(\times 10^{4}\right)\end{array}$ & $\begin{array}{c}\text { WLIP } \\
\text { rank }\end{array}$ & Section & $\begin{array}{c}\text { Sum } \\
\text { of } A_{\text {effi }}\end{array}$ & $\begin{array}{c}A_{\text {effi }} \\
\text { rank }\end{array}$ & $\begin{array}{c}\text { WLIP } \\
\left(\times 10^{4}\right)\end{array}$ & $\begin{array}{c}\text { WLIP } \\
\text { rank }\end{array}$ \\
\hline A 1 & 0.205 & 30 & 0.154 & 30 & D 1 & 1.309 & 23 & 0.574 & 26
\end{tabular}




\begin{tabular}{lllll|lllll} 
A 2 & 1.229 & 25 & 0.980 & 21 & D 2 & 3.025 & 12 & 1.450 & 3 \\
A 3 & 1.469 & 22 & 1.005 & 17 & D 3 & 4.537 & 4 & 1.760 & 1 \\
A 4 & 1.685 & 21 & 1.032 & 16 & D 4 & 4.330 & 7 & 1.394 & 4 \\
A 5 & 1.175 & 26 & 0.988 & 18 & D 5 & 3.132 & 11 & 1.209 & 7 \\
B 1 & 0.526 & 28 & 0.386 & 27 & E 1 & 2.067 & 19 & 0.911 & 22 \\
B 2 & 2.181 & 17 & 1.090 & 14 & E 2 & 4.423 & 5 & 1.114 & 10 \\
B 3 & 2.539 & 16 & 1.133 & 9 & E 3 & 5.947 & 2 & 1.500 & 2 \\
B 4 & 2.823 & 14 & 1.113 & 11 & E 4 & 6.004 & 1 & 1.262 & 5 \\
B 5 & 1.288 & 24 & 0.986 & 19 & E 5 & 4.632 & 3 & 0.767 & 24 \\
C 1 & 0.311 & 29 & 0.234 & 29 & F 1 & 1.979 & 20 & 0.881 & 23 \\
C 2 & 2.154 & 18 & 1.100 & 13 & F 2 & 3.479 & 10 & 1.046 & 15 \\
C 3 & 3.764 & 9 & 1.245 & 6 & F 3 & 4.405 & 6 & 1.108 & 12 \\
C 4 & 2.776 & 15 & 1.137 & 8 & F 4 & 3.766 & 8 & 0.580 & 25 \\
C 5 & 1.129 & 27 & 0.985 & 20 & F 5 & 2.856 & 13 & 0.311 & 28 \\
\hline
\end{tabular}

\subsubsection{Proposed locations of water deluge system location}

Based on the WLIPs calculated in the previous step, the proposed locations for water deluge nozzles can be suggested by their index rank. Fig. 11 presents high-ranking positions assuming 12 water deluge nozzles with their leak locations for the selected fire scenarios.

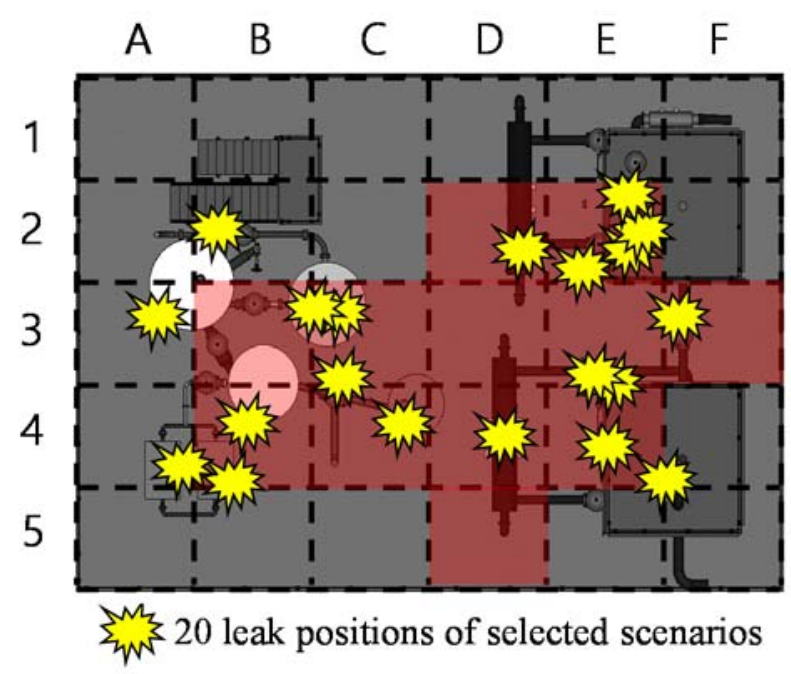

Fig. 11. 12 high-ranking locations by WLIP.

The leak locations are generally covered by the high-ranking positions, but some leak locations are not covered by water deluge nozzles due to their low fire frequencies. Also, the high- 
ranking positions generally include the equipment on the process deck. However, to include all of the equipment in the operating radius of the water nozzles, 12 nozzles are not sufficient. The proposed method in this study cannot suggest the proper number of deluge nozzles for an offshore installation. Thus, the final decision regarding the locations of water deluge nozzles should be based on the results of WLIP analyses and engineering judgments.

\subsection{Verification of locations of water deluge system selected by the proposed method.}

To verify the efficiency of the water deluge model selected using the proposed method in the previous chapter (in Fig. 11), a comparison model is used. In the comparison model, the water deluge nozzles are uniformly distributed as shown in Fig. 12. In the fire CFD simulation, the KFX (2013) CFD tool was used for the verification. KFX uses the k- $\varepsilon$ turbulence model. The $\mathrm{k}-\varepsilon$ model is, by far, the most widely used turbulence model in engineering applications. Also, the Eddy Dissipation Concept (EDC) turbulence combustion model is the combustion model used in KFX.

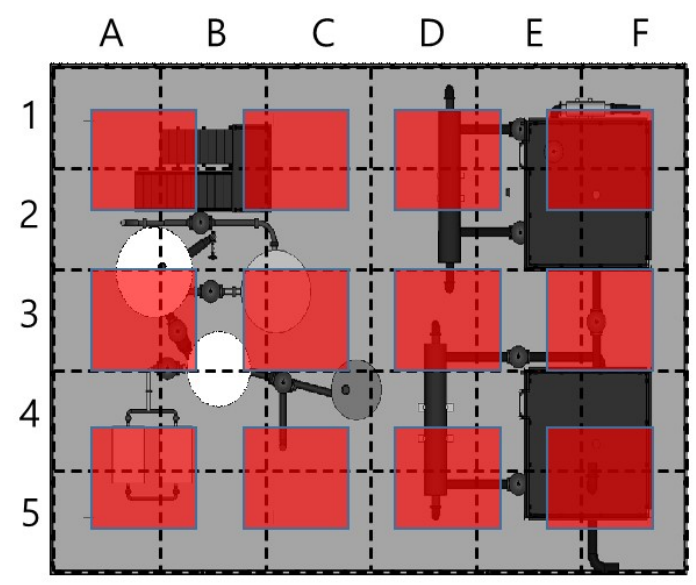

Fig. 12. Twelve uniformly distributed water deluge nozzles of the comparison model.

\subsubsection{Validation of KFX CFD simulation}

The option for modelling a water spray system is provided in the KFX. By comparing the existing experiment for the heat reduction effect of a spray system on an indoor pool fire (Gupta et al., 2013) with the CFD analysis, the reliability of the spray option in KFX is confirmed. The experiment generated a variety of results for the application of a water mist system in the indoor pool fire experiment. Fig. 13 shows the arrangement of the general experiment. Fig. 14(a) illustrates the position of the thermocouple used to measure the temperature, and Fig. 14(b) presents the position of the spray nozzle and the spray injection angle used. In this experiment, $\mathrm{C}_{7} \mathrm{H}_{16}$ (n-heptane) was the fuel for the pool fire. 


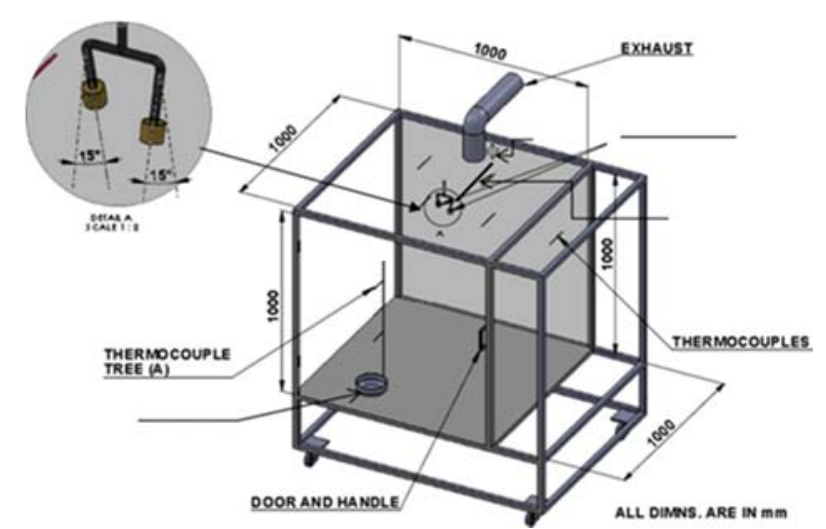

Fig. 13. Schematic of experiment (Gupta et al., 2013).
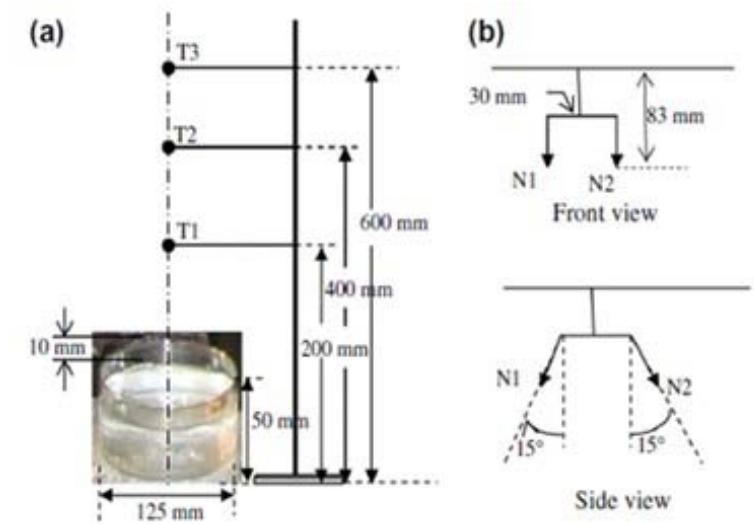

Fig. 14. Experimental arrangement in the test chamber; (a) thermocouple tree and (b) atomiser orientation (Gupta et al., 2013).

In addition, as determined by the spray pressure (4-8 bars), various kinds of spray operating systems were created. In all of the scenarios, the spray system was set to operate 30 seconds after ignition. The results of the temperature distribution at each location of the pool position were proposed. To acquire the result corresponding to the experimental case for ignition at the midpoint of the double chamber, a pressure of 7 bars was selected for the comparison target. Based on the data generated by the experiment, CFD analysis is performed using KFX. To check the heat reduction effect, two conditions - spray system operation and non-operation are applied. As a result, an analysis space $\left(1 \mathrm{~m}^{3}\right)$ identical to the size of the chamber is created, and the equivalent spray operating conditions are identified (see Table 5).

Table 5. Spray operating conditions.

\begin{tabular}{ccccc}
\hline $\begin{array}{c}\text { Operating } \\
\text { pressure } \\
(\mathrm{bar})\end{array}$ & $\begin{array}{c}\text { Gas low rate } \\
(1 / \mathrm{min})\end{array}$ & $\begin{array}{c}\text { Water flow rate } \\
(\mathrm{ml} / \mathrm{min})\end{array}$ & $\begin{array}{c}\text { SMD* } \\
(\mu \mathrm{m})\end{array}$ & $\begin{array}{c}\text { Average } \\
\text { velocity } \\
(\mathrm{m} / \mathrm{s})\end{array}$ \\
\hline $7 \pm 0.1$ & $66 \pm 3$ & $107 \pm 2.5$ & 22.4 & 2.8 \\
\hline
\end{tabular}

*SMD: Sauter mean diameter of droplets 
To adopt the actual conditions of the experiment in KFX, information on the number of droplets sprayed per hour is required. However, because that was not specified, the flow rate and droplet size information is used to estimate a value. Fig. 15 compares the experimental result and the result of CFD analysis using KFX. At 30 seconds, when the spray began to operate, the temperature drops and the two similar temperature distributions are checked. However, there is a difference of about 3 seconds in the delay in the decrease of temperature between the experiment and the CFD result. This difference may be explained by the number of droplets being estimated using the flow rate and droplet size. Also, the sensitivity of thermocouple may affect the decrease of temperature. Through the procedure described above, the use of the CFD technique to model the water spray system is validated.

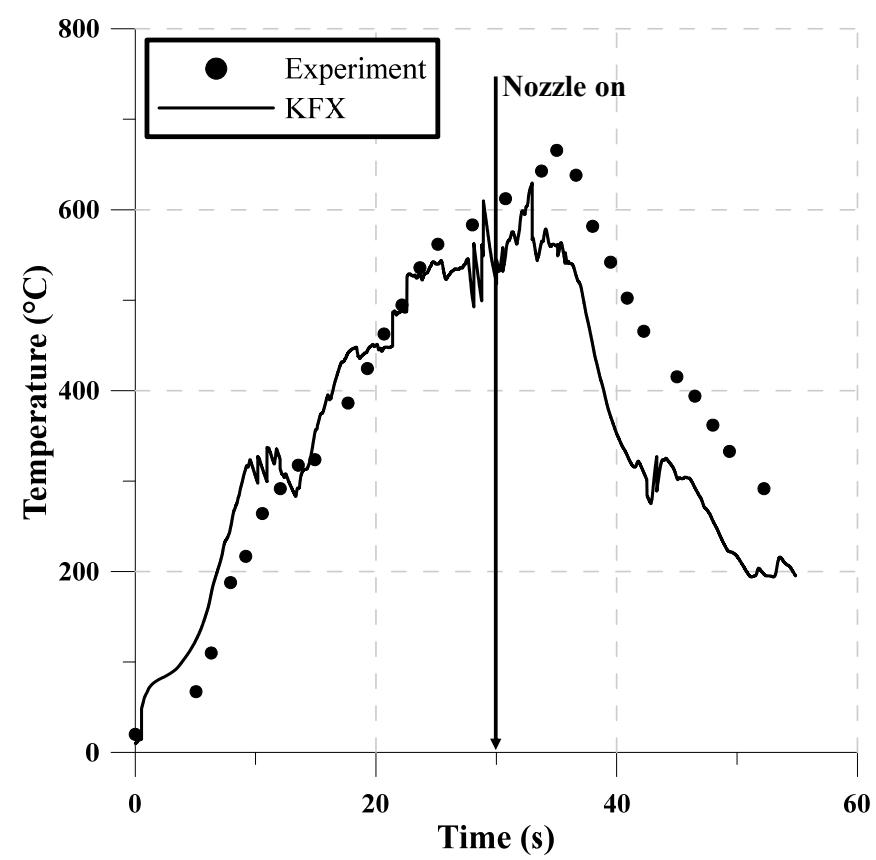

Fig. 15. Comparison between CFD result and experimental result.

\subsubsection{Fire CFD simulations}

Fig. 16 shows the target structure and simulation volume modelled in KFX. The columns and handrail were removed in the KFX model. The 'ignition in ignition cells' method of KFX is used as the ignition method in this study. A heat flux of $6 \mathrm{~kW} / \mathrm{m}^{2}$ is imposed on the oil pool cells from the adjacent ignition cells, and the ignition is turned off if the maximum temperature in the field is raised to half of the adiabatic temperature. 


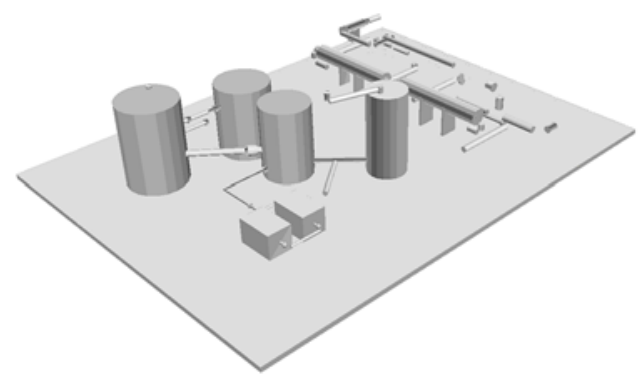

(a) KFX model

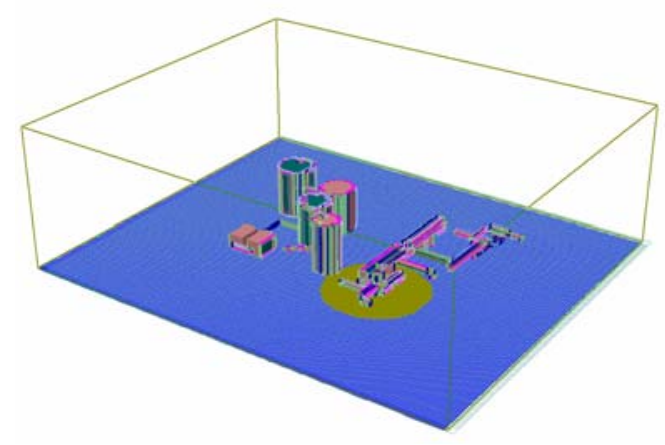

(b) Analysis volume

Fig. 16. KFX model and analysis volume.

To ensure the number of grid cells, grid convergence studies are performed by varying the number of grid cells. Fig. 17 presents the grid cell distributions of three analysis cases for the grid convergence studies. The fine grid cells are generated in the region of the topside structure. In contrast, the grid cells outside the topside structure have a relatively large size. Fig. 18 shows the results of the convergence studies in terms of temperature escalations. A convergence is achieved when the number of grid cells is 3.9 million.

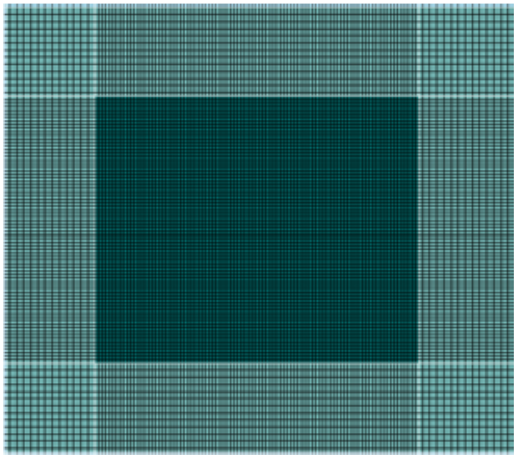

(a) Case 1 (1.3 million)

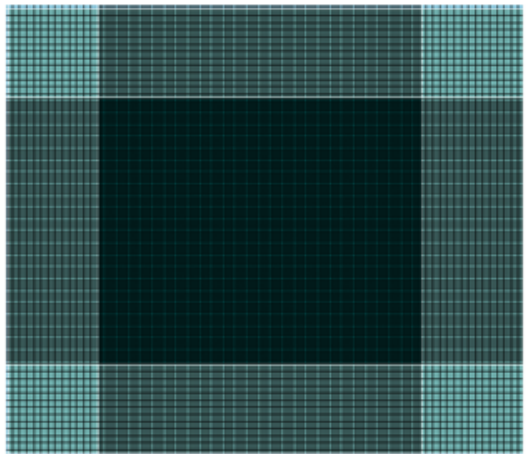

(b) Case 2 (3.9 million)

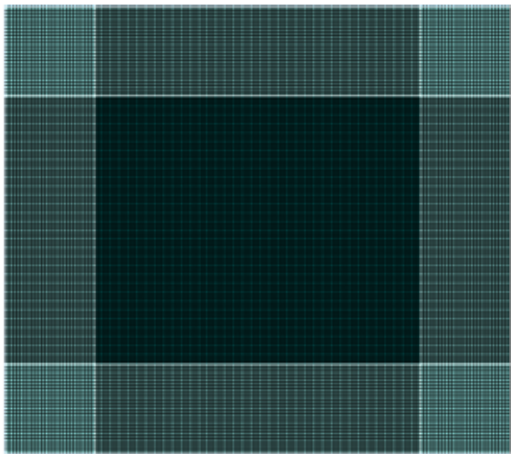

(c) Case 3 (5.1 million)

Fig. 17. Grid cell distributions of analysis cases for grid convergence studies. (The values in parentheses indicate the numbers of grid cells.) 


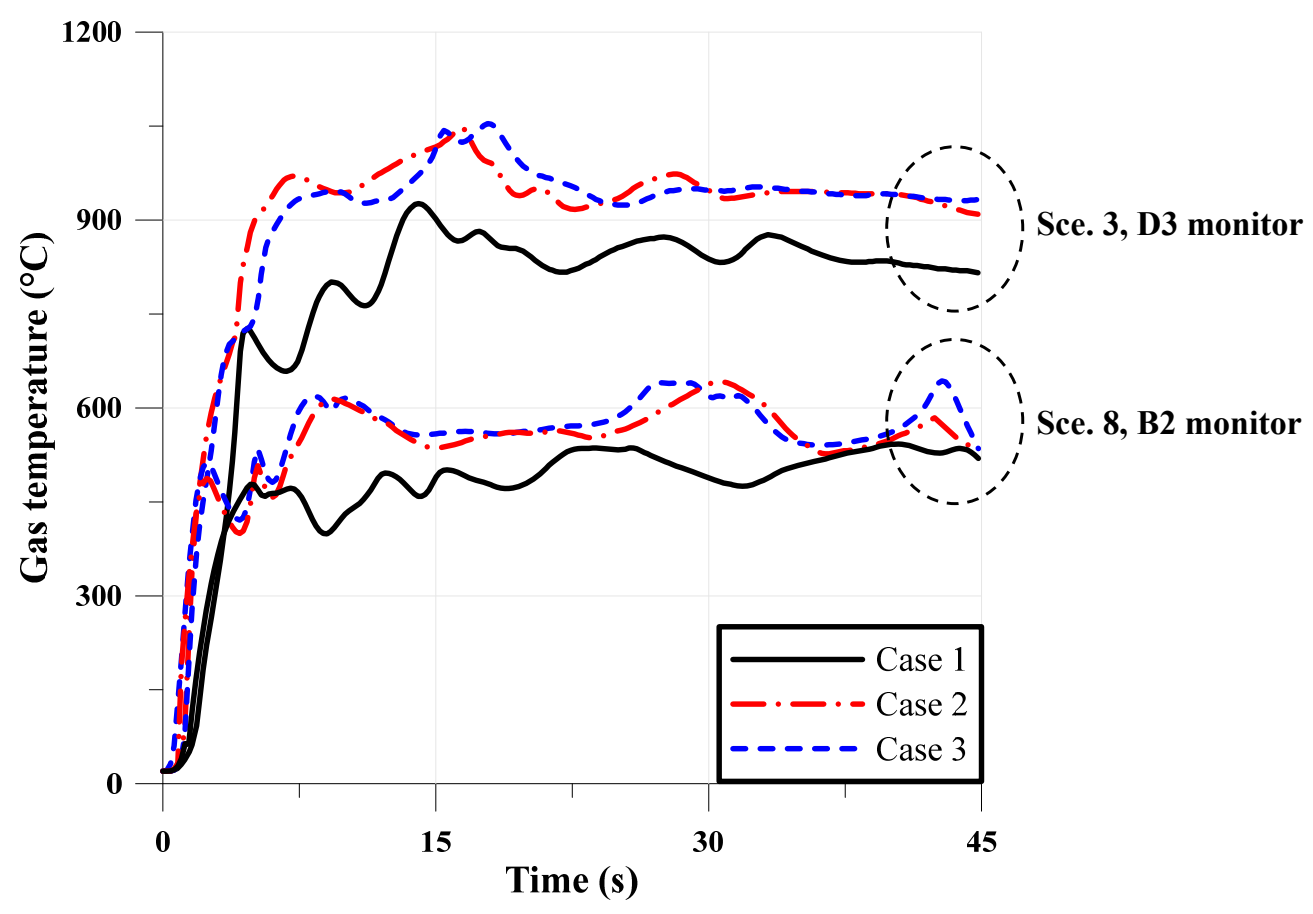

Fig. 18. The grid convergence studies to determine the number of grid cells.

\subsubsection{Obtaining the fire loads in spaces for the calculation of WLIP}

Three elevations $(0.5,1.5$ and $2.5 \mathrm{~m})$ are selected to locate the monitoring points, which are equally spaced to obtain the fire loads as shown in Fig. 19. At each section of each elevation, five monitoring points are used to obtain the average fire loads. The total number of monitoring points is 450 , and the average fire load at each section from the 15 monitoring points is applied to verify the effects of the water deluge models.

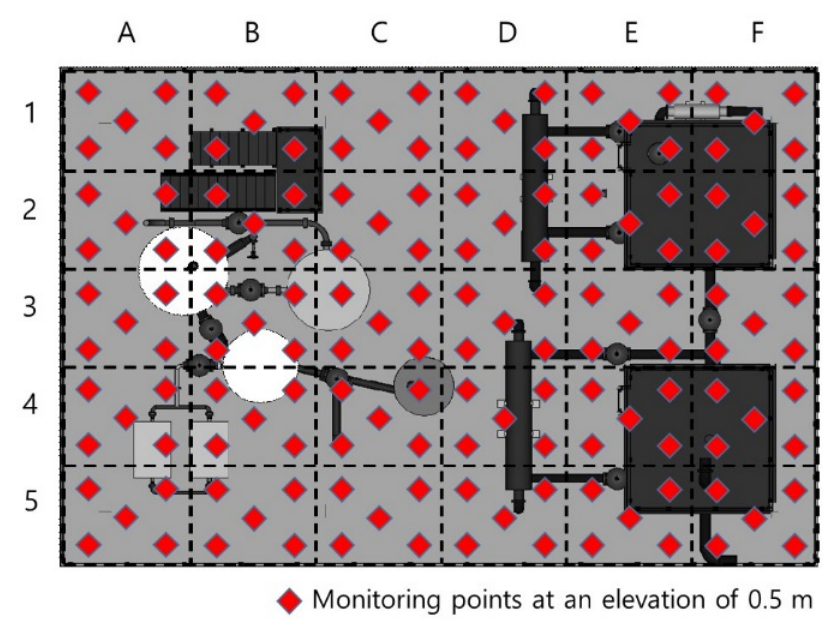

Fig. 19. Location of monitoring points used for obtaining temperature. 


\subsubsection{CFD simulation results}

Fig. 20 shows three-dimensional rendered images of the simulation result for scenario 17 at each time. The water deluge systems operate after 45 seconds, and the pool fires are suppressed in 3 seconds.

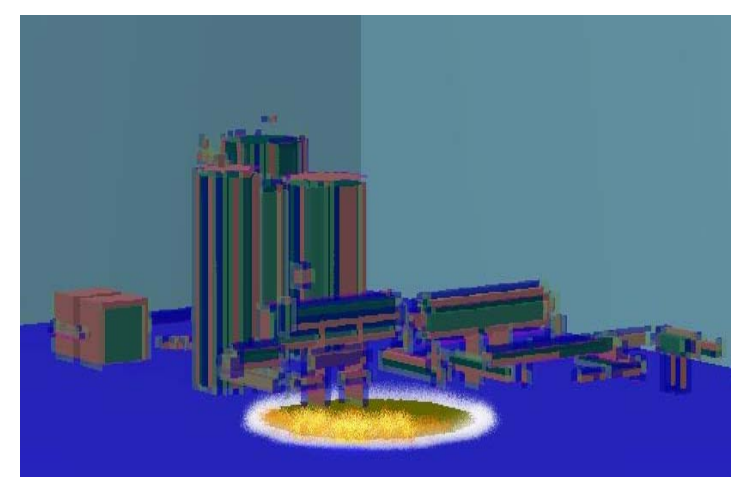

(a) After 0.35 seconds

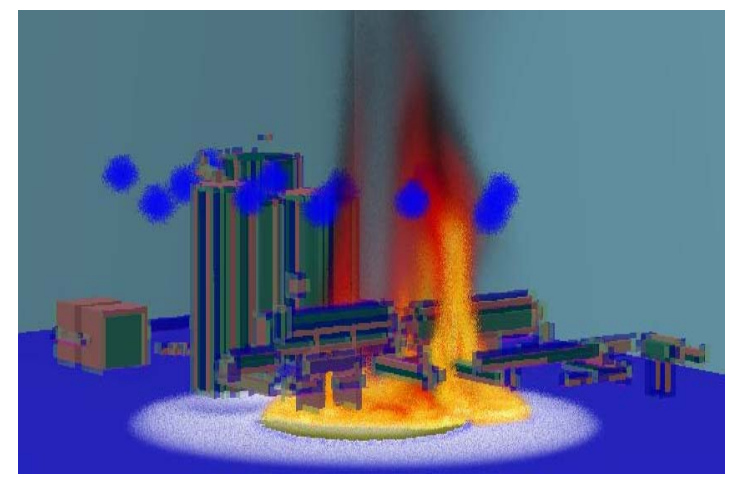

(c) After 45.0 seconds (Deluge on)

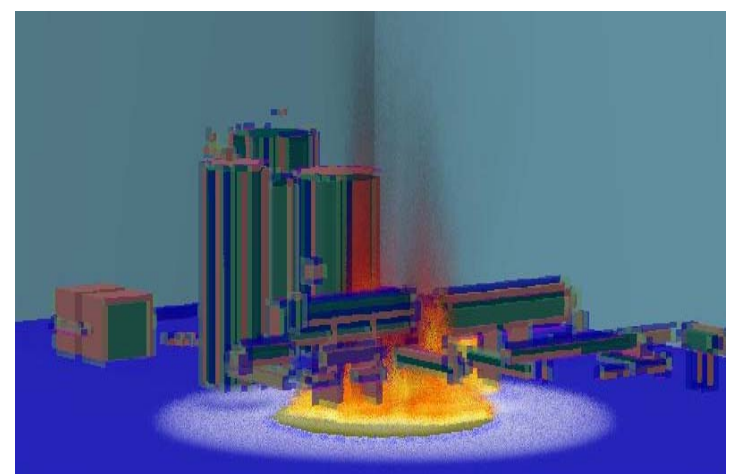

(b) After 40.0 seconds

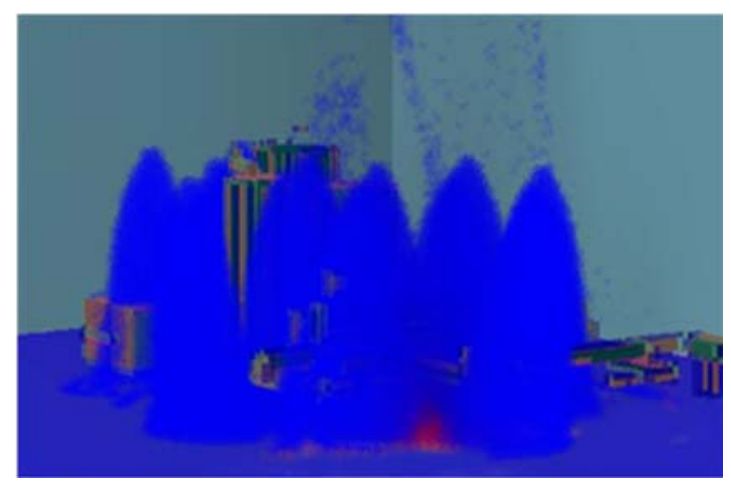

(d) After 48.0 seconds

Fig. 20. Three-dimensional simulation result for scenario 17 at each time.

From the simulations of 20 fire scenarios, the average temperatures at each section of the monitoring points are obtained. Fig. 21 indicates the time-dependent temperature results of three representative scenarios with water spray locations established with the proposed method. The temperature is the average temperature of the area in each section. The temperature at the monitors fluctuates with the shape of pool fire, interaction with structures, turbulence and wind. In case of monitor D3 in Fig. 21 (a), the temperature sharply climbs to $0 \sim 11$ seconds. After 11 seconds, the temperature decreases and stabilises at about $150^{\circ} \mathrm{C}$. The centre of the flame in the initial time steps is located at the edge of the oil pool because double heat fluxes are imposed on the oil pool cell at the edge of the pool, according to the 'ignition in ignition cells' method as shown in Fig. 22. Thus, the temperature at monitor D3 decreases as the shape of pool fire stabilises after $11 \mathrm{~s}$. 

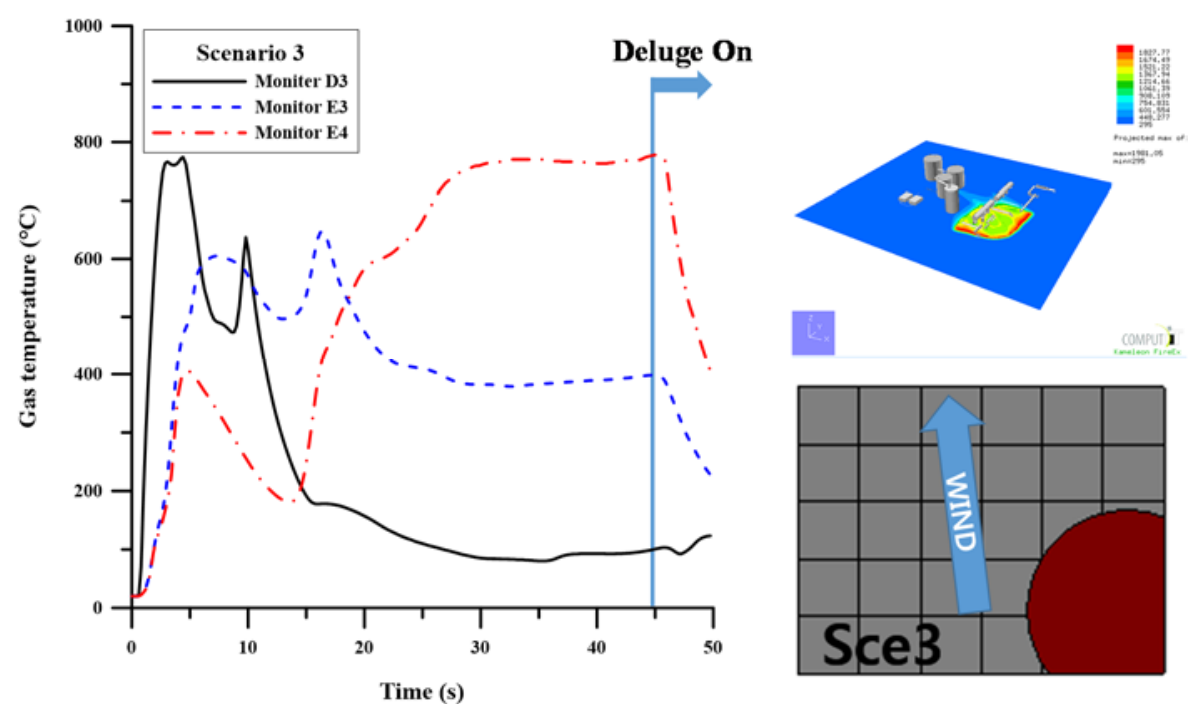

(a) Scenario 3
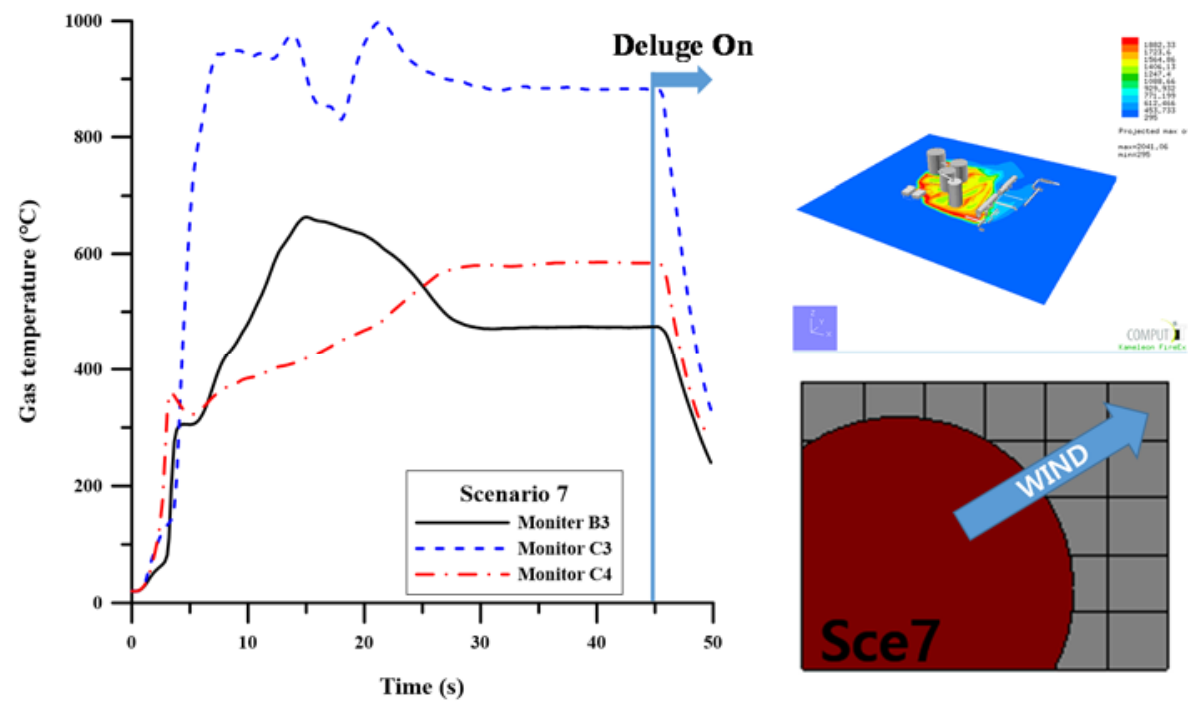

(b) Scenario 7
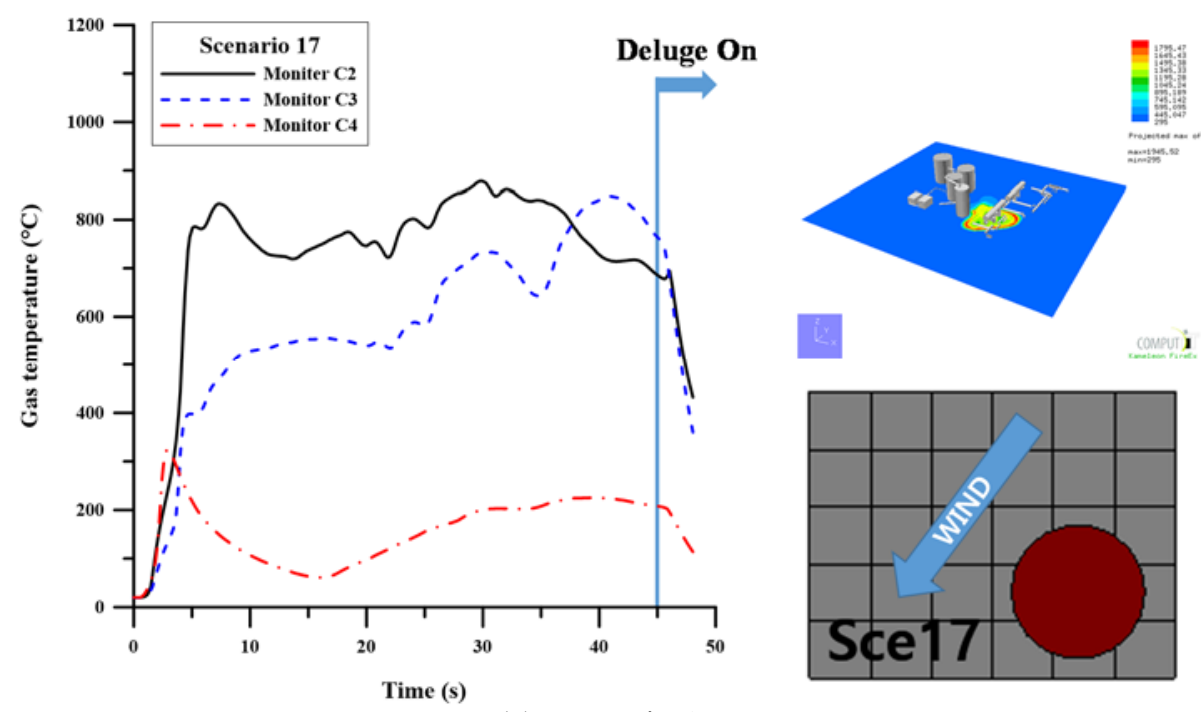

(c) Scenario 17

Fig. 21. Time versus gas temperature curves of each scenario. 


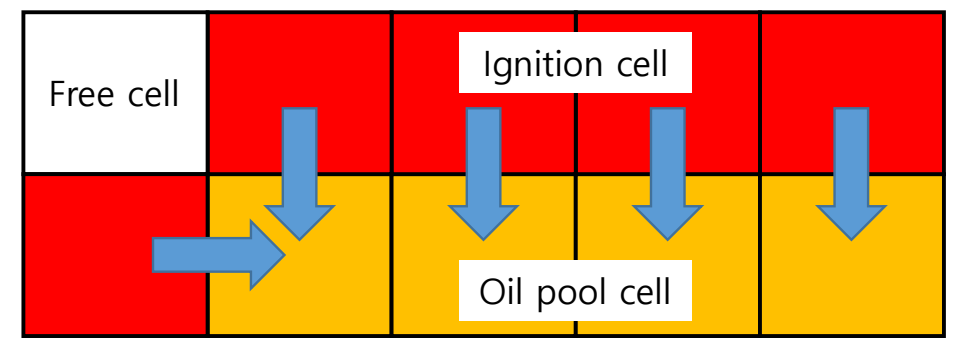

A heat flux of $6 \mathrm{~kW} / \mathrm{m}^{2}$

Fig. 22. Schematic of 'ignition in ignition cells' method of KFX.

\subsubsection{Verification of efficiency of the proposed methodology}

By calculating and comparing the sizes of the heated areas with a temperature lower than a critical temperature, the performance of the WLIP model is verified. The elevated temperature response for human individuals is described in NORSOK (2010). Humans experience difficulty in mouth breathing at temperatures above $149{ }^{\circ} \mathrm{C}$, which is the maximum temperature for escape. The rules and standards for fire protection found in DNV-GL (2008) identified $450{ }^{\circ} \mathrm{C}$ as the critical temperature of structural steel and ordinary reinforcing steel. According to the assumed critical temperatures for humans and structures, the two water deluge models are compared.

Fig. 23 presents the result for the temperature distribution of scenario 3. Without a water deluge system, $38 \%$ of the total area is classified as unsafe. After 3 seconds of deluge systems operation, in the case of WLIP model, the unsafe area decreases by $14 \%$, and in the case of comparison model, the unsafe area shrinks by $24 \%$. The yellow zone indicates a critical area for humans, and the red zone indicates a critical area for both humans and structures. 


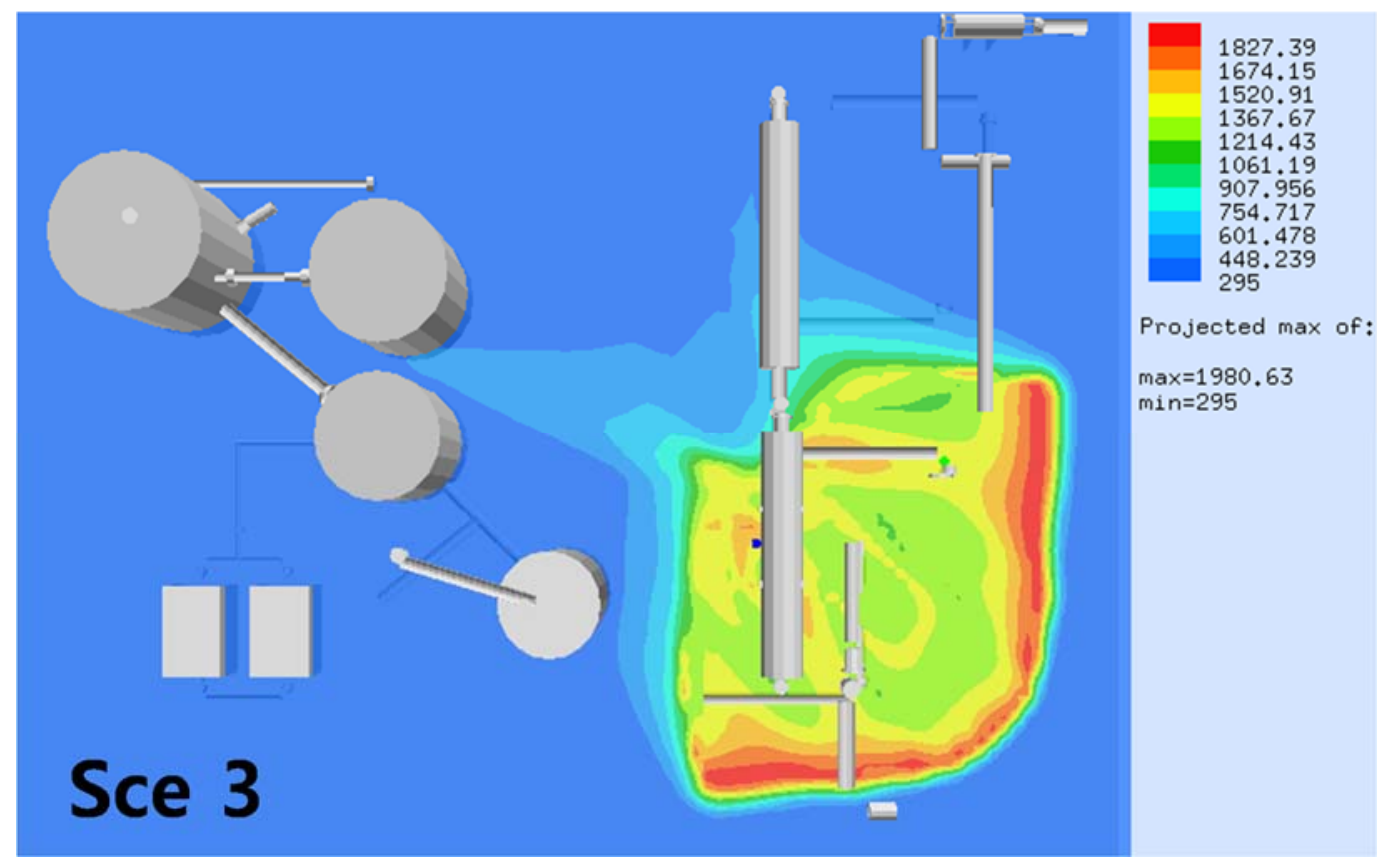

(a) Temperature distribution of scenario 3 at 44.5 seconds (without water deluge operation).
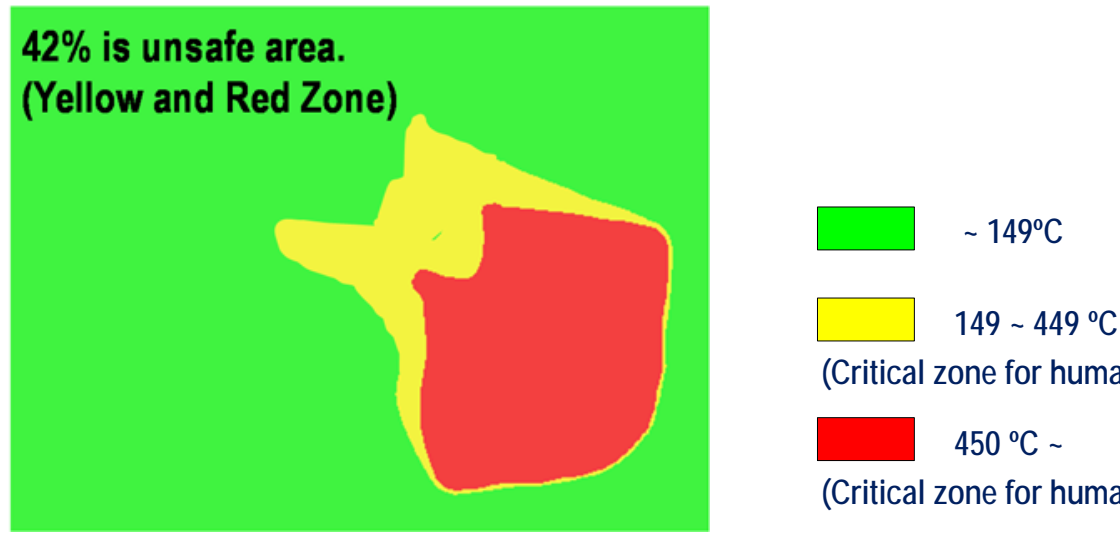

(Critical zone for humans)

$450^{\circ} \mathrm{C} \sim$

(Critical zone for humans and structures)

(b) Heated area at 44.5 seconds (without water deluge operation).

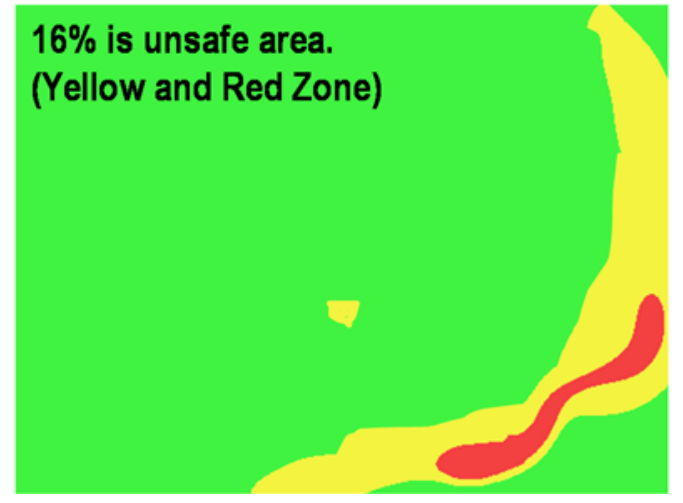

(c) Heated area at 48 seconds (WLIP model)

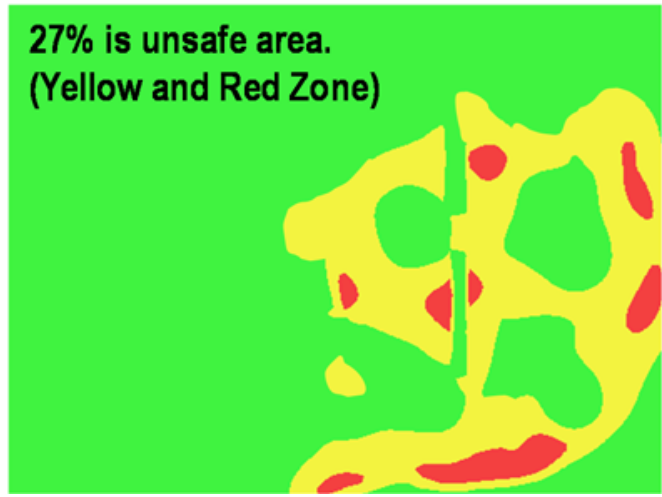

(d) Heated area at 48 seconds (comparison model)

Fig. 23. The results of the temperature distribution and heated area computations for scenario 17 at each time. 
Table 6 shows the results of the heated areas computations at 48 seconds (after 3 seconds of water deluge systems operation) for the WLIP model and comparison model.

The control of the growth of a fire can be evaluated by checking the shrinkage of the heated area. In this study, the concept of risk is borrowed to compare the effectiveness of the WLIP and comparison models, using the heated area as the consequence.

Risk may be defined as the product of fire frequency and their consequences (Paik et al., 2011). Therefore, risk increases with the increase of event likelihood/probability or event consequences. Normally, the consequences of risk can be expressed as factors that directly affect human life, property and the environment, such as temperature, heat flux, pressure and the extent of a spill. It is not suitable to calculate risk using the heated area as a consequence because the heated area does not directly affect casualties or property damage. In terms of efficiency in case of a fire accident, it is advantageous that the water nozzles are located with a relatively high frequency. To consider fire frequency, the effectiveness of the two models is compared by borrowing the concept of risk.

Figs. 24 and 25 show the risk value calculated with the heated area (i.e., consequence) and the frequency of each scenario. The results show that the WLIP model is more efficient in terms of the control over fire loads than the comparison model.

Table 6. The results of the heated areas computations for WLIP model and comparison model.

\begin{tabular}{|c|c|c|c|c|c|c|}
\hline \multirow{2}{*}{$\begin{array}{c}\text { Scenario } \\
\text { no. }\end{array}$} & \multicolumn{3}{|c|}{ Size of heated area $\left(\mathrm{m}^{2}\right)$, above $149^{\circ} \mathrm{C}$} & \multicolumn{3}{|c|}{ Size of heated area $\left(\mathrm{m}^{2}\right)$, above $450{ }^{\circ} \mathrm{C}$} \\
\hline & $\begin{array}{c}\text { Without } \\
\text { water deluge }\end{array}$ & $\begin{array}{l}\text { WDIP } \\
\text { model }\end{array}$ & $\begin{array}{l}\text { Comparison } \\
\text { model }\end{array}$ & $\begin{array}{c}\text { Without } \\
\text { water deluge }\end{array}$ & $\begin{array}{l}\text { WDIP } \\
\text { model }\end{array}$ & $\begin{array}{c}\text { Comparison } \\
\text { model }\end{array}$ \\
\hline Sce 1 & 33.56 & 13.12 & 17.78 & 13.37 & 1.72 & 3.16 \\
\hline Sce 2 & 7.20 & 0.00 & 3.78 & 2.95 & 0.00 & 0.20 \\
\hline Sce 3 & 110.13 & 40.01 & 50.54 & 45.64 & 6.62 & 9.13 \\
\hline Sce 4 & 7.16 & 3.08 & 2.31 & 2.87 & 0.22 & 0.74 \\
\hline Sce 5 & 11.01 & 5.91 & 2.47 & 4.14 & 3.04 & 0.39 \\
\hline Sce 6 & 0.02 & 0.00 & 0.00 & 0.11 & 0.00 & 0.00 \\
\hline Sce 7 & 298.37 & 193.88 & 221.83 & 110.44 & 64.35 & 75.21 \\
\hline Sce 8 & 190.43 & 77.61 & 115.78 & 88.47 & 23.43 & 28.46 \\
\hline Sce 9 & 23.94 & 13.15 & 11.57 & 5.90 & 2.87 & 2.77 \\
\hline Sce 10 & 23.82 & 7.84 & 6.51 & 6.16 & 2.89 & 1.46 \\
\hline
\end{tabular}




\begin{tabular}{lcccccc} 
Sce 11 & 0.77 & 0.00 & 0.00 & 0.19 & 0.00 & 0.00 \\
Sce 12 & 37.02 & 16.11 & 20.72 & 11.11 & 3.03 & 4.12 \\
Sce 13 & 171.07 & 111.14 & 127.29 & 72.47 & 28.81 & 40.04 \\
Sce 14 & 90.47 & 50.72 & 55.34 & 34.97 & 11.80 & 14.44 \\
Sce 15 & 24.86 & 3.43 & 14.90 & 9.88 & 0.93 & 3.82 \\
Sce 16 & 38.43 & 220.33 & 17.48 & 11.05 & 7.85 & 5.39 \\
Sce 17 & 72.47 & 50.78 & 57.95 & 24.72 & 11.49 & 15.17 \\
Sce 18 & 145.26 & 93.10 & 107.24 & 58.58 & 34.15 & 35.84 \\
Sce 19 & 29.94 & 12.56 & 20.58 & 10.07 & 1.62 & 4.90 \\
Sce 20 & 88.41 & 64.78 & 71.34 & 38.16 & 17.91 & 22.45 \\
\hline Average & 70.22 & 38.88 & 46.27 & 27.56 & 11.29 & 13.38 \\
\hline
\end{tabular}

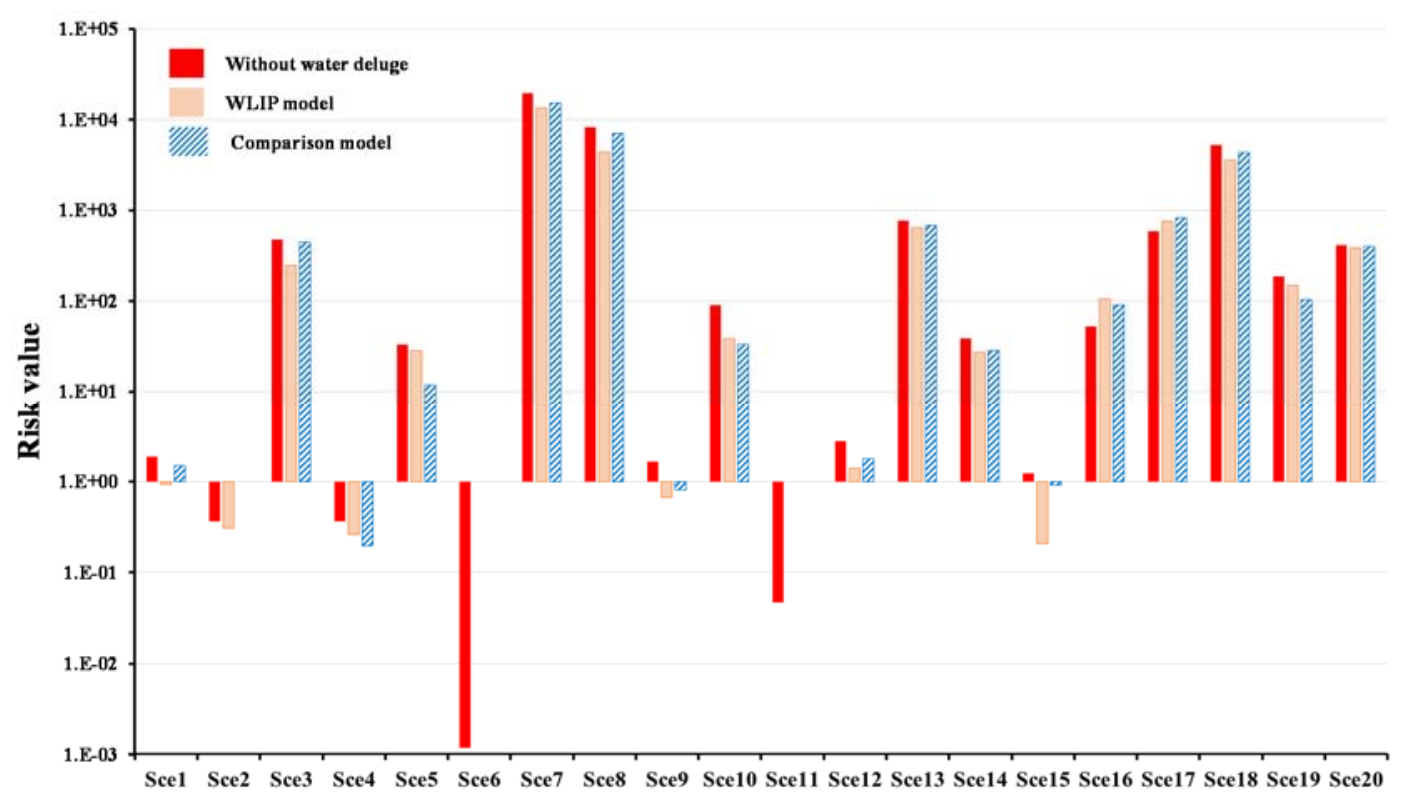

(a) Risk value based on the size of the heated area, above $149{ }^{\circ} \mathrm{C}$. 


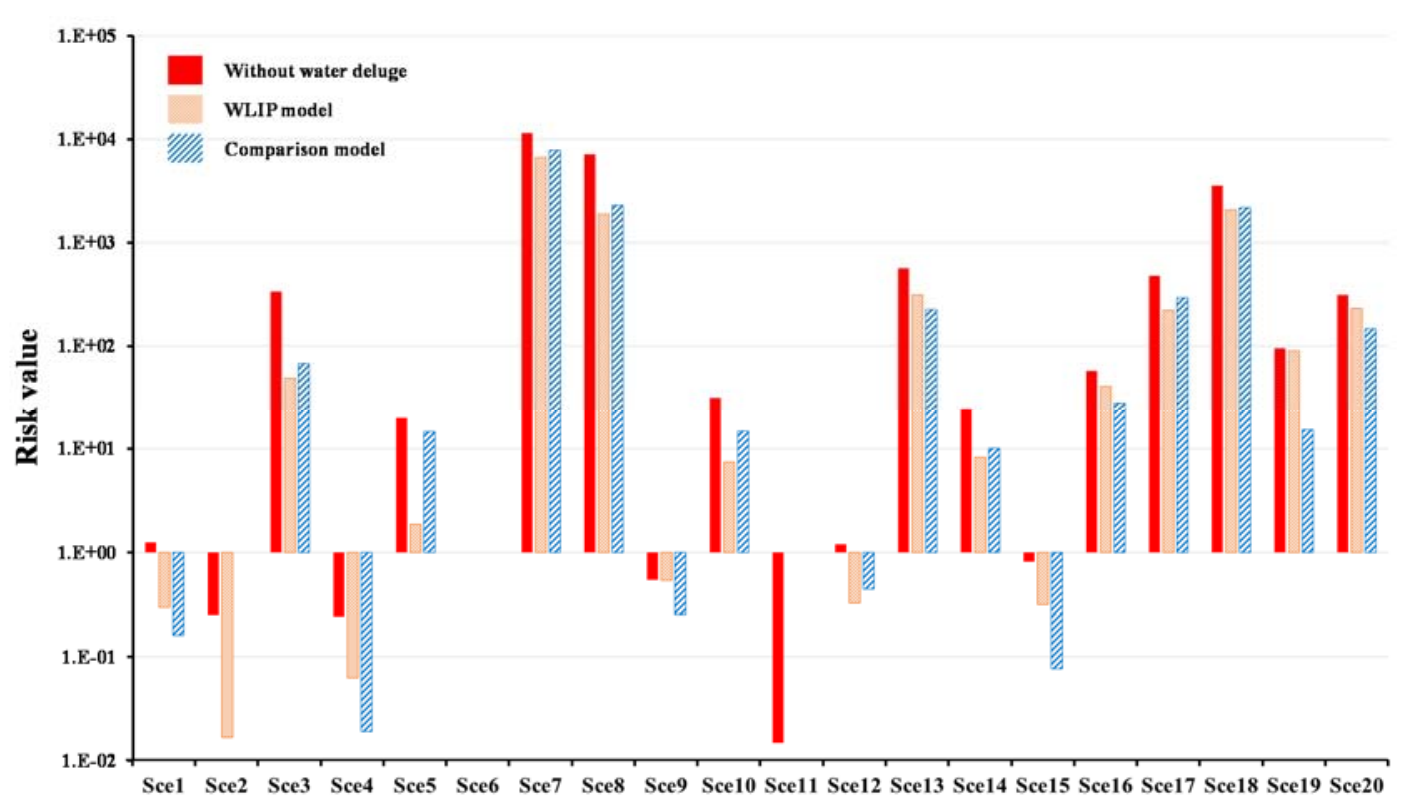

(b) Risk value based on the size of the heated area, above $450{ }^{\circ} \mathrm{C}$.

Fig. 24. Risk values based on the size of the heated area in each scenario.

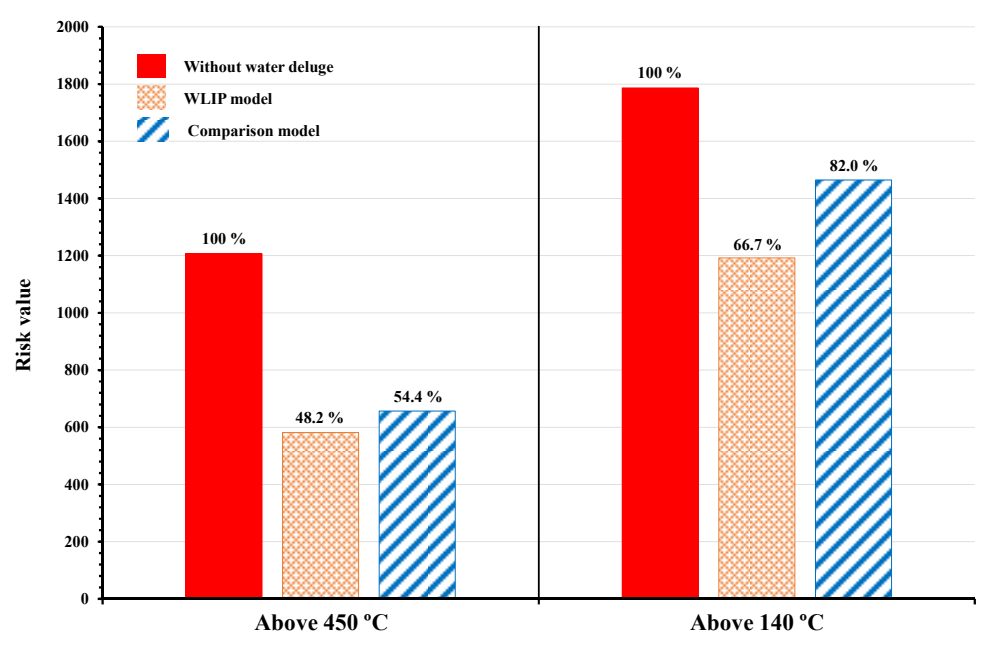

Fig. 25. Average risk values of each water deluge model in the pool fire accidents.

Fig. 26 shows the exceedance curve at representative sections, which is calculated using the gas temperature (i.e., consequence) and the frequency for each scenario. The exceedance curve describes the probability that the levels of consequence are exceeded. According to international regulations, NORSOK (2010) and ISO 19900 use a threshold probability of exceedance level $\left(10^{-4}\right.$ per year $)$ as the risk criteria to determine the fire design loads for structural response analysis.

These results show that the use of selected locations for water deluge nozzles, as determined 
by the proposed methodology, can efficiently reduce the fire design loads of pool fire accidents when compared with a uniform arrangement. In the case of sections B2 and C2, the fire design load of the WLIP model is larger than the comparison model because the water nozzle is not located at these sections in the WLIP model. However, the fire design loads of sections B2 and $\mathrm{C} 2$ are even below $400{ }^{\circ} \mathrm{C}$ without water deluge systems, so they do not have a substantial effect in terms of structural integrity.

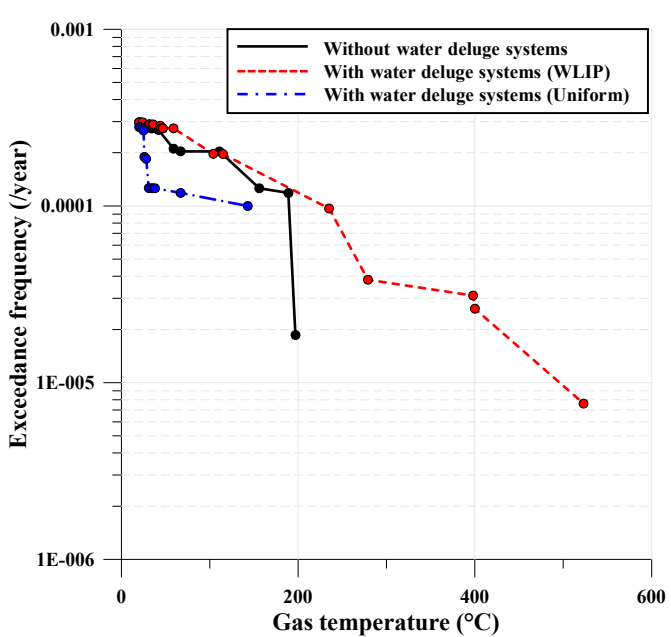

(a) B2 section

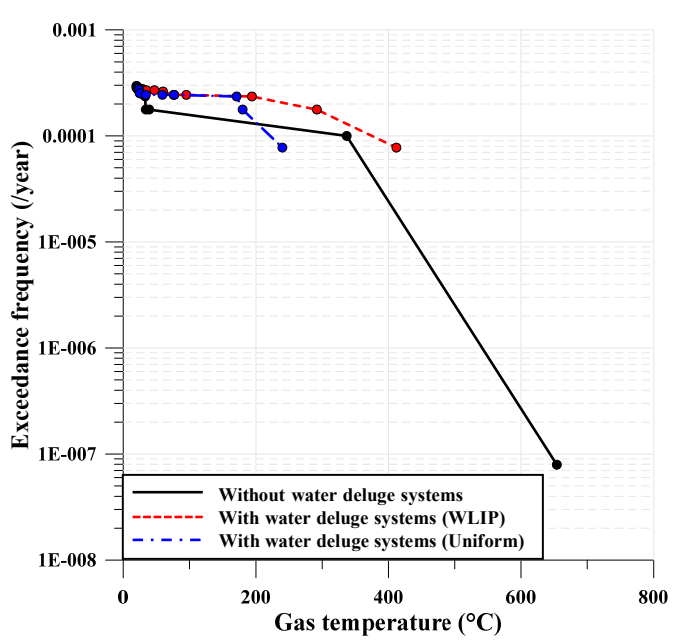

(c) $\mathrm{C} 2$ section

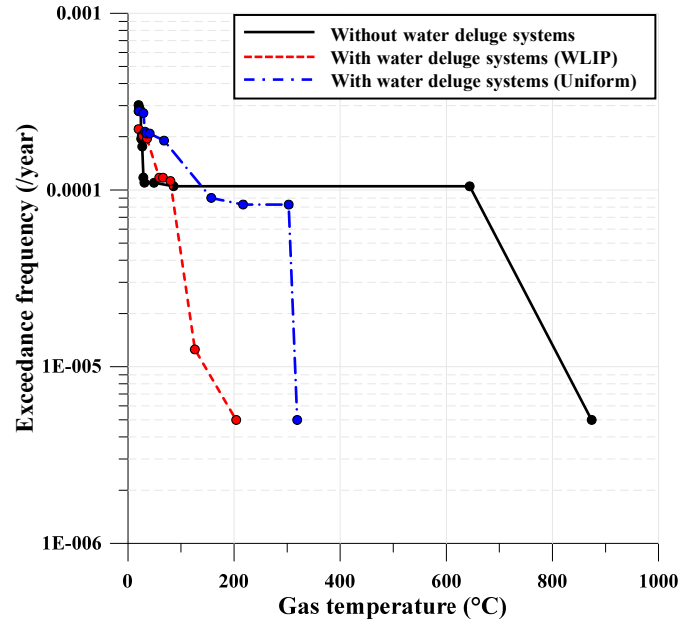

(b) B4 section

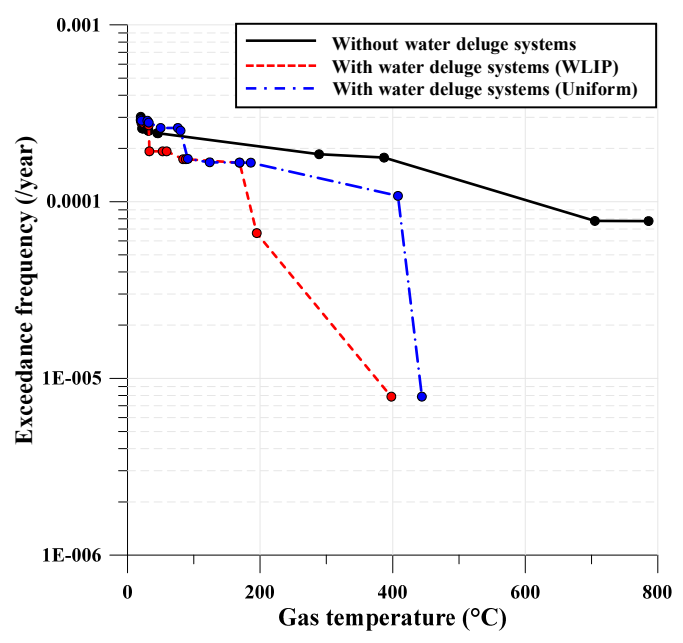

(d) $\mathrm{C} 4$ section 


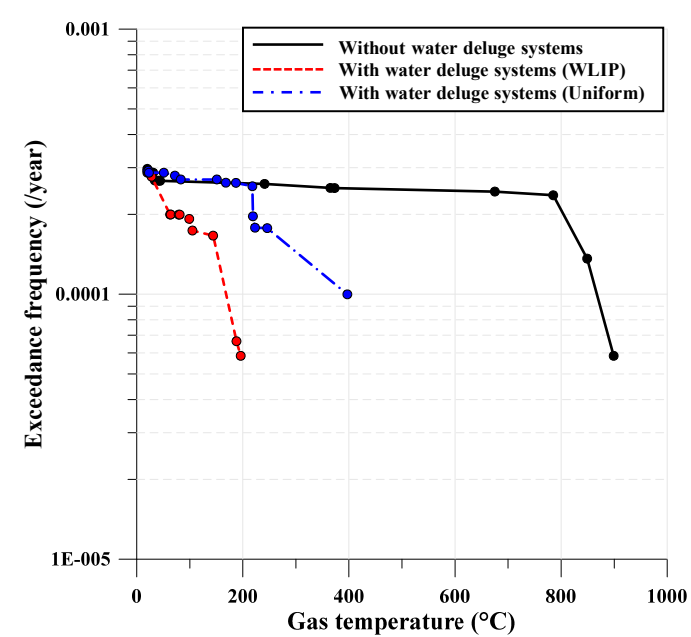

(e) $\mathrm{D} 2$ section

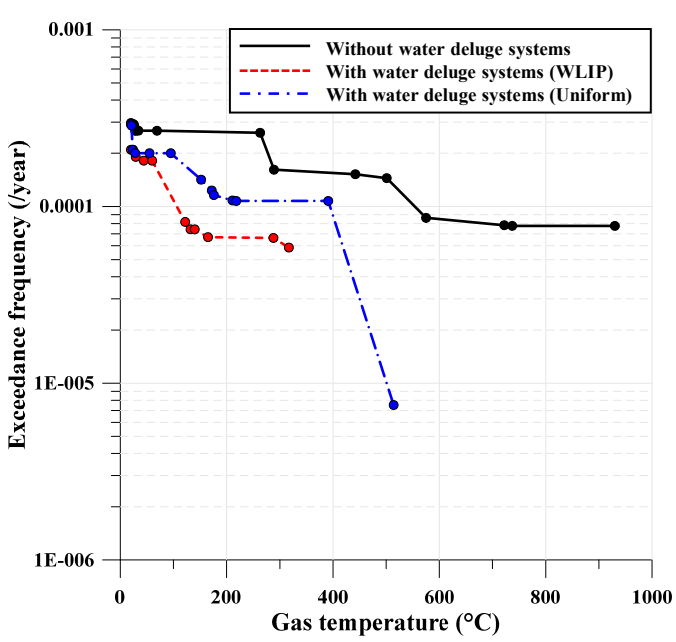

(g) E2 section

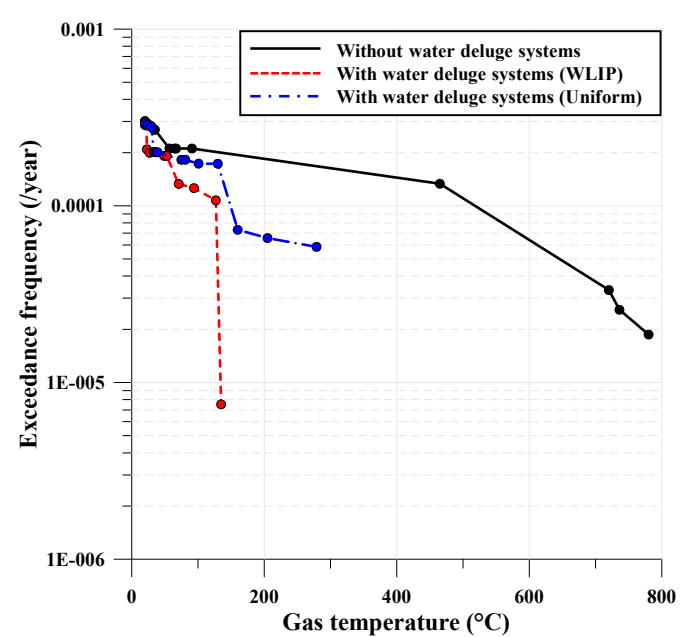

(f) D4 section

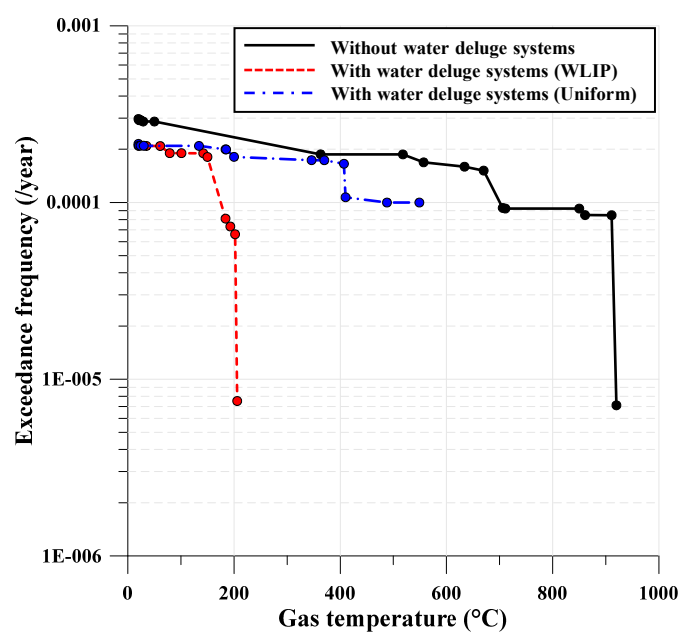

(h) E4 section

Fig. 26. Gas temperature exceedance curve at each section.

\section{Concluding remarks}

The aim of this study is to suggest a new method for the selection of water deluge nozzles to efficiently prevent and reduce the risk of pool fire accidents. The water deluge index for pool fires (WLIP) is calculated using the pool area and the frequency of fire scenarios. As the pool area is calculated with a simple equation, oil spill CFD analysis can be used to yield more precise results. The reliability of the WLIP is validated using risk-based comparison, which shows that the WLIP is more efficient than uniformly distributed nozzles in reducing the risk of pool fire accidents.

However, the proposed method in this study cannot provide the proper number of deluge nozzles for an offshore installation. That number may depend on cost-benefit analysis and on the level of risk to personnel, equipment and other potential hazards of the location. Thus, 
engineering judgments are still important for determining the final locations of water deluge nozzles with reference to the results of WLIP analyses.

Water deluge systems are among the active protection systems commonly used to reduce the consequences of fire accidents. The designers of such systems should recognise the importance of selecting system locations after considering their related costs and effectiveness. The proposed WLIP can help them to determine system locations to ensure safety and protect against pool fires on onshore and offshore installations.

A subsequent study can consider developing a method which integrates all types of fire accidents (jet fires, pool fires and other types of fires).

\section{Acknowledgements}

This research was supported by the Basic Science Research Program through the National Research Foundation of Korea (NRF) funded by the Ministry of Science, ICT \& Future Planning (NRF-2017R1A2B4004891).

\section{References}

ABS. 2014. Guidance noted in fire-fighting systems. American Bureau of Shipping, Texas, USA.

Alarifi A.A., Dave J., Phylaktou H.N., Aljumaiah O.A., Andrews G.E. 2014. Effects of firefighting on a fully developed compartment fire: Temperatures and emissions. Fire Safety Journal, 68: 71-80.

Anderson, T.W., Darling, D.A. 1954. A Test of Goodness-of-Fit. Journal of the American Statistical Association. 49: 765-769.

API. 2017. Recommended practice for analysis, design, installation, and testing of safety systems for offshore production facilities. API RP 14C. American Petroleum Institute, D.C., USA.

Cook J., Bahrami Z., Whitehouse R.J. 1990. A comprehensive program for calculation of flame radiation levels. Proceedings of the First International Conference on Loss of Containment, London, UK.

Czujko J., Paik J.K. 2012a. Hydrocarbon explosion and fire engineering: Assessing and managing hydrocarbon explosion and fire risks in offshore installations. Marine Technology, 23-25.

Czujko J., Paik J.K. 2012b. Paradigm change in safety design against hydrocarbon explosions and fires. FABIG Newsletter, 60: 20-38.

DeFriend S., Dejmek M., Porter L., Deshotels B., Natvig B. 2008. A risk-based approach to flammable gas detector spacing. Journal Hazard Material, 159:142-151.

Dembele S., Tam V.H.Y., Ferraris S., Rosario R.A.F., Wen J.X. 2007. Effectiveness of water deluge in fire suppression and mitigation, IChemE Symposium Series No. 153. 
Institution of Chemical Engineers. Rugby, UK.

DNV·GL. 2008. Fire protection. DNV-OS-D301. Det Norske Veritas, Oslo, Norway.

Gosse A.J., Hankinson G. 2001. Use of water deluge to minimise hazards of oil and gas fires offshore, Proceedings of the 2001 International Gas Research Conference, Amsterdam, Netherlands, 5-8 Nov.

Gupta M., Pasi A., Ray A., Kale S.R. 2013. An experimental study of the effects of water mist characteristics on pool fire suppression. Experimental Thermal and Fluid Science, 44: 768-778.

Hankinson G., Lowesmith B.J. 2004. Effectiveness of area and dedicated water deluge in protecting objects impacted by crude oil/gas jet fires on offshore installations. Journal of Loss Prevention in the Process Industries, 17:(2) 119-125.

Himoto K., Tanaka T. 2012. A model for the fire-fighting activity of local residents in urban fires. Fire Safety Journal, 54: 154-166.

HSE. 2000. Offshore hydrocarbon release statistics 2000, Offshore Technology Report N. OTO 2000-112. Health and Safety Execution, London, UK.

ISO. 1999. Petroleum and natural gas industries - Control and mitigation of fires and explosions on offshore production installations - Requirements and guidelines, International standard ISO 13702, Geneva: International Organization for Standardization.

Jee M.H., Moon C.K., Kim H.Y. 2013. Performance-based fire fighting strategies for confined fire zones in nuclear power plants. Progress in Nuclear Energy, 62: 16-25.

KFX. 2013. User's manual for Kameleon Fire EX. Computational Industry Technologies AS, Stavanger, Norway.

Kim S.J., Lee D.H., Hong H.M., Ahn S.H., Park J.B., Seo J.K., Kim B.J., Paik J.K. 2016. Methods for determining the optimal arrangement of water deluge systems on offshore installations. Ocean Engineering, 114: 236-249.

LR. 2014. Rules and regulations for the classification of offshore units: Guidelines for the calculation of probabilistic explosion loads. Lloyd's Register, Southampton, UK.

McCaffrey B.J. 1984. Jet diffusion flame characteristics and the effects of water deluge, Combustion Science Technology, 40: 107-136.

Mudan K.S. 1995. SFPE handbook of fire protection engineering. Quincy, MA: National Fire Protection Association.

Nolan D.P. 1996. Handbook of fire and explosion protection engineering principles for oil, gas, chemical, and related facilities. Saddle River, NJ: Noyes Publications.

NORSOK. 2010. NORSOK Standard Z-013: Risk and emergency preparedness assessment. 3rd edition. NORSOK, Oslo, Norway.

OGP. 2010a. Process release frequency. Report No. 434-01. International Association of Oil \& Gas Producers, London, UK.

OGP. 2010b. Risk assessment data directory: ignition probabilities. Report No. 434-6.1. International Association of Oil \& Gas Producers, London, UK.

Paik J.K. 2011. Report No. EFEF-04: Explosion and fire engineering of FPSOs (Phase III): Nonlinear structural consequence analysis. Korea Ship and Offshore Research Institute, Pusan National University, Busan, Korea.

Paik J.K, Czujko J. 2009. Report No. EFEF-01: Explosion and fire engineering of FPSOs 
(Phase I): Feasibility study with literature review. Korea Ship and Offshore Research Institute, Pusan National University, Busan, Korea.

Paik J.K., Czujko J. 2010. Report No. EFEF-03: Explosion and fire engineering of FPSOs (Phase II): definition of design explosion and fire loads. Korea Ship and Offshore Research Institute, Pusan National University, Busan, Korea.

Paik J.K., Czujko J. 2011. Assessment of hydrocarbon explosion and fire risks in offshore installations: Recent advances and future trends. IES Journal Part A: Civil \& Structural Engineering, 4(3): 167-179.

Paik J.K., Czujko J. 2012. Engineering and design disciplines associated with hydrocarbon explosion and fire risks in offshore oil and gas facilities. Transactions of the Society of Naval Architects and Marine Engineers, 120: 1-39.

Paik J.K., Czujko J., Kim B.J., Seo J.K., Ryu H.S., Ha Y.C., Janiszewski P., Musial B. 2011. Quantitative assessment of hydrocarbon explosion and fire risks in offshore installations. Marine Structures, 24: 73-96.

Prasad K., Li C., Kailasanath K. 1999. Simulation of water mist suppression of small scale methanol liquid pool fires, Fire Safety Journal, 33: 185-212.

Seo J.K., Kim D.C., Ha Y.C., Kim B.J., Paik J.K. 2013. A methodology for determining efficient gas detector locations on offshore installations. Ships and Offshore Structures, 8(5): 524-535.

Spouge J. 1999. A guide to quantitative risk assessment for offshore installations. DNV Technica, Oslo, Norway.

Svensson S. 2002. A study of tactical patterns during fire fighting operations. Fire Safety Journal, 37:(7) 673-695.

UKOOA/HSE. 2006. Fire and explosion guidance, Part 2: Avoidance and mitigation of fires. 152-RP-48. UK: fireandblast.com Ltd.

UKOOA. 2006. Ignition probability review, model development and look-up correlations, IP research report. Energy Institute, HSE, UKOOA, London, UK.

Vinnem J.E. 2007. Offshore risk assessment: Principles, modelling and application of QRA studies. Springer, Stavanger, Norway.

Walker S., Bleach R., Carney S., Fairlie G., Louca L.A. 2003. New guidance on the design of offshore structures to resist the explosion hazard. Proceedings of the 32nd International Conference on Ocean, Offshore and Arctic Engineering, Cancun, Mexico.

Ye K.Q. 1998. Orthogonal column Latin hypercubes and their application in computer experiments. Journal of the American Statistical Association, 93(444): 1430-1439. 